\title{
Tornadoes and the global anisotropy of the physical space
}

\author{
Yuriy Alexeevich Baurov ${ }^{1,4}$, *, Igor Fedorovich Malov², Francesco Meneguzzo ${ }^{3}$ \\ ${ }^{1}$ Closed Joint Stock Company Research Institute of Cosmic Physics, Moscow Region, Korolyov, Pionerskaya, Russia \\ ${ }^{2}$ Pushchino Radio Astronomy Observatory, P.N.Lebedev Physical Institute, Russian Academy of Sciences, Moscow Region, Pushchino, \\ Russia \\ ${ }^{3}$ Institute of Biometeorology, National Research Council, Firenze, Via Caproni, Italy \\ ${ }^{4}$ Present address: Hotwater Srl, San Miniato (PI), Via Gioberti, Italy
}

\section{Email address:}

baurov@mail.ru (Yu.A. Baurov),malov@prao.ru (I.F. Malov), f.meneguzzo@ibimet.cnr.it (F. Meneguzzo)

\section{To cite this article:}

Yuriy Alexeevich Baurov, Igor Fedorovich Malov, Francesco Meneguzzo. Tornadoes and the Global Anisotropy of the Physical Space. American Journal of Modern Physics. Vol. 3, No. 2, 2014, pp. 93-112. doi: 10.11648/j.ajmp.20140302.19

\begin{abstract}
Whereas the basic physical mechanisms leading to the onset and evolution of tornadoes have been well established, some progress can still be useful to identify the conditions supporting the development of a tornado towards a violent or catastrophic stage, as well as possible specific and observable events triggering the onset of a tornado in a generally favorable atmospheric environment. On the basis of an assumed global anisotropy of the physical spaceand the associated non-gauge byuon theory, an additional mechanism of energy accumulation in the process of development of a tornado to its mature stage is proposedand its consistency is checked against a dataset of individual tornadoes as well as of tornado outbreaks. The results point to a significant link between the angle formed by the cosmological vector potentialrepresenting the global anisotropy of the physical space and the surface tangent to the local Earth's surface and the occurrence of the most energetic tornadoes; as a consequence, such tornadoes are shown to occur only at specific times of the day depending on latitude, longitude and day of the year. Moreover, a further additional mechanism is proposed for the early origin of a tornado, on the basis of the interaction of a large peak current lightning discharge with the cosmological vector potential introduced by the byuon theory. It is shown how, in the framework of the proposed theory, a fraction of the energy of a tornado at its onset stage can originate from the self-energy associated with the formation of the physical space of elementary particles located along the lightning discharge. The verification of the proposed mechanism for the onset of tornadoes is delayed to later time when suitable data sets will be available.
\end{abstract}

Keywords: Tornado, Fujita scale, Anisotropy of the physical space, Byuon theory, Lightning

\section{Introduction}

The nature of the origin of tornadoes, especially those developing into violent ones (F3 to F5 on the Fujita scale) has always been of great interest for researchers, since the destructive energy of such tornadoes is comparable with the energy of nuclear explosions, i.e. on the order of 20 kton of TNT, or $10^{14} \mathrm{~J}[1]$.

A great deal of theoretical and modeling work was performed regarding the onset and time evolution of tornadoes[1-3], as well as very effective conceptual models were developed, as summarized byKufa and Snow [4].

Numerical simulations of real tornadoes sometimes suffer from significant underestimation of their intensity, even using the most advanced mesoscale or local scale meteorological models, such as the state of the art WRF-
NMM model used inLitta et al. [5]: their F3 tornado occurred in India was simulated as a much weaker F0 one (peak wind speed around $20 \mathrm{~ms}^{-1}$ against the observed $70 \mathrm{~ms}^{-1}$ ), that is most of its real energy was not caught by the simulation.Nevertheless, such models have been successfully used for the simulation and prediction of the local atmospheric "ingredients" leading to tornadoes[6].

Besides the maximum intensity based on damages (Fujita classification) which is heavily dependent upon the strength of the winds inside the tornado, recently the path length and the path width of a tornado were included in a more comprehensive and physically consistent analysis of its overall energy in the effort to derive a power law describing the temporal behavior of tornadoes analogously to Earthquakes [7].

In the subject of lightning, their main parameters as well 
as the process of their development from the leader stroke to the return stroke, including possible multiplicity, are presented in several works [8,9]; as well, a large observational evidence exist about the connection between lightning and tornadoes, such as summarized in Price[10]where it was tornadoes are associated with certain lightning signatures, in particular with a "jump" in total lightning ( $\mathrm{IC}+\mathrm{CG}$ ) few minutes before tornado touchdown and a shift in the CG lightning polarity to a positive one around the time of tornado sightings.

The prevalence of the otherwise relatively rare positive cloud to ground lightning flashes $(+\mathrm{CG})$ around the time of tornado formation or touchdown is especially relevant because $+\mathrm{CG}$ carry on average one order of magnitude larger electric currents than their negative counterparts (CG) with peak currents up to more than 200kA[9,11,12].

InMarshall and Stolzenburg[13] an extensive review of lightning in different moist convective environments is performed, setting the upper and lower limits of the energy produced by the lightning flashes to $10^{10} \mathrm{~J}$ and $10^{7} \mathrm{~J}$, respectively, the upper limit for $\mathrm{CG}$ flashes being later reduced to about $2 \cdot 10^{9} \mathrm{~J}[14]$. It can be stated therefore that a CG flash can develop a quantity of energy 4 to 5 orders of magnitude less than the most violent tornadoes.

Some additional contribution could still be useful to explain the origin and source of the huge energy of the most powerful tornadicevents, both at their onset and in the course of their development in time; this is the subject of the present work and will be performed in the frame of a known physical theory not yet applied to the field of atmospheric sciences.

The paper is organized as follows: Section 2 describes the datasets used for the verification of the proposed physical processes concerning the development of tornadoes; in Section 3 theoretical insights are proposed about the byuon theory and the global anisotropy of the physical space (Section3.1.), the role of such anisotropy for the additional energy supply to tornadoes (Section3.2.), as well as a proposed mechanism for the onset of tornadoes from very large peak current lightning (Section3.3.);
Section4 shows the results of the verification of the processes explained in Section3.2. as well as the respective discussion. The conclusions and the perspectives for further work are set out in Section 5, the last of this article.

\section{Tornado Datasets}

The verification of the hypothesis and the processes proposed in this article would require in principle the construction of datasets including both tornado events and the associated lightning data. Nevertheless, as explained in Section 3.3., at the present time sufficient detail is not available for the needed lightning data and the verification will be limited to the processes described in Section 3.2. that are based upon the link between tornadoes, discriminated on the basis of their overall energy, and the global anisotropy of the physical space.

Therefore, only data concerning tornadoes are needed at this stage of the research, including date, time, peak intensity, geographical coordinates of tornado's touchdown and its path length.

Tornado reporting worldwide lags very much behind the quality used in the U.S.A., to which country therefore refer most of the data use in this article.

The first dataset includes 139 violent tornadoes, i.e. F3 to F5 on the Fujita scale, from the period 1989 to October, 2013. The selection of the tornado events was performed picking up at least the most intense event from several outbreaks occurred in the 25-years period, provided that the touchdown (TD) time and the path length were available, as well that the most intense event were at least an F3. For several outbreaks more than one event were included provided they were sufficiently distant in space (at least about $0.5^{\circ}$ in latitude or longitude) and/or in time (at least about one hour), resulting in a total of 83 outbreaks with 42 tornadoes classified as F3, 76 events in the class F4 and 21 catastrophic F5 tornadoes, all hitting the U.S.A. except one F5 event occurred in Manitoba, Canada.

Table1 lists the above mentioned 139 tornado events.

Table1.Tornado events used to build Fig. 4, Fig. 5(a) and Fig. 5(b) in Section 4. In the "Source" column, the abbreviations PE, SE and CA refer to the tornado events dealt with in Perez et al. [15],Seimon [16] and Carey et al.[17], respectively; SPC [18] and THP [19] refer to databases of tornado events. It's to be noted that the sources SPC and THP were used throughout the listed tornado events. The standard abbreviations for the U.S. States as well as for the Time zones were used. The abbreviation TD stays for "touchdown". In the "Outbreak" column the F4 and F5 events belonging to the tornado outbreaks listed in Table 2 and used to build Fig. $6(a-v)$ are indicated.

\begin{tabular}{|c|c|c|c|c|c|c|c|c|}
\hline Source & $\begin{array}{l}\text { U.S. States } \\
\text { or Country }\end{array}$ & Date & TD time & $\begin{array}{l}\text { Time } \\
\text { zone }\end{array}$ & $\begin{array}{c}\text { TD Lat } \\
\left(^{\circ}\right)\end{array}$ & $\begin{array}{c}\text { TD Lon } \\
\left(^{\circ}\right)\end{array}$ & $\begin{array}{c}\text { Path } \\
\text { length } \\
(\mathrm{km}) \\
\end{array}$ & Outbreak \\
\hline \multicolumn{9}{|c|}{ F3 Intensity class } \\
\hline $\mathrm{SPC}+\mathrm{THP}$ & $\mathrm{TX}$ & 27-May-97 & 1:27 PM & CST & 31.100 & -97.367 & 2.2 & \\
\hline $\mathrm{SPC}+\mathrm{THP}$ & TX & 27-May-97 & 12:46 PM & CST & 31.300 & -97.367 & 5.9 & \\
\hline $\mathrm{SPC}+\mathrm{THP}$ & $\mathrm{IN}$ & 18-Oct-07 & 9:03 PM & EST & 38.333 & -85.317 & 7.7 & \\
\hline $\mathrm{SPC}+\mathrm{THP}$ & $\mathrm{AL}$ & 10-Jan-08 & 4:20 PM & CST & 33.283 & -87.300 & 7.8 & \\
\hline $\mathrm{SPC}+\mathrm{THP}$ & NY & 31-May-98 & 5:30 PM & EST & 42.533 & -75.083 & 8.0 & \\
\hline $\mathrm{SPC}+\mathrm{THP}$ & $\mathrm{KS}$ & 15-May-95 & 9:20 PM & $\mathrm{CST}$ & 37.883 & -100.667 & 9.6 & \\
\hline $\mathrm{SPC}+\mathrm{THP}$ & $\mathrm{KS}$ & 16-May-95 & 5:16 PM & CST & 37.983 & -100.867 & 9.6 & \\
\hline $\mathrm{SPC}+\mathrm{THP}$ & $\mathrm{OK}$ & 3-May-99 & $2: 20 \mathrm{PM}$ & CST & 34.883 & -98.317 & 9.7 & \\
\hline
\end{tabular}




\begin{tabular}{|c|c|c|c|c|c|c|c|c|}
\hline Source & $\begin{array}{l}\text { U.S. States } \\
\text { or Country }\end{array}$ & Date & TD time & $\begin{array}{l}\text { Time } \\
\text { zone }\end{array}$ & $\begin{array}{l}\text { TD Lat } \\
\left({ }^{\circ}\right)\end{array}$ & $\begin{array}{l}\text { TD Lon } \\
\left({ }^{\circ}\right)\end{array}$ & $\begin{array}{l}\text { Path } \\
\text { length } \\
(\mathbf{k m})\end{array}$ & Outbreak \\
\hline $\mathrm{SPC}+\mathrm{THP}$ & OK & 10-May-10 & 4:48 PM & CDT & 35.333 & -97.083 & 11.0 & \\
\hline SPC+THP & KY & 18-Oct-07 & 7:09 PM & CST & 37.450 & -87.083 & 12.0 & \\
\hline $\mathrm{SPC}+\mathrm{THP}$ & $\mathrm{NC}$ & 15 -Nov-08 & $3: 10 \mathrm{AM}$ & EST & 35.483 & -77.517 & 13.0 & \\
\hline $\mathrm{SPC}+\mathrm{THP}$ & PA & 31-May-98 & 8:00 PM & EST & 40.483 & -75.750 & 13.3 & \\
\hline $\mathrm{SPC}+\mathrm{THP}$ & OK & 3-May-99 & 2:46 PM & CST & 34.967 & -98.117 & 14.0 & \\
\hline $\mathrm{SPC}+\mathrm{THP}$ & GA & $13-F e b-00$ & 11:42 PM & EST & 31.233 & -84.217 & 14.4 & \\
\hline $\mathrm{SPC}+\mathrm{THP}$ & $\mathrm{TX}$ & 27-May-97 & 3:05 PM & $\mathrm{CST}$ & 30.500 & -97.833 & 14.7 & \\
\hline SPC+THP & $\mathrm{TX}$ & 25-Dec-12 & 9:05 AM & CST & 31.167 & -95.317 & 15.6 & \\
\hline $\mathrm{SPC}+\mathrm{THP}$ & MS & 10-Jan-08 & 11:51 AM & $\mathrm{CST}$ & 32.583 & -89.533 & 16.0 & \\
\hline $\mathrm{SPC}+\mathrm{THP}$ & OK & 3-May-99 & 7:41 PM & CST & 35.767 & -98.150 & 19.0 & \\
\hline $\mathrm{SPC}+\mathrm{THP}$ & PA & 31-May-98 & 7:50 PM & EST & 39.817 & -79.083 & 20.8 & \\
\hline $\mathrm{SPC}+\mathrm{THP}$ & IL & 7-Jan-08 & 3:30 PM & $\mathrm{CST}$ & 42.267 & -88.383 & 21.0 & \\
\hline $\mathrm{SPC}+\mathrm{THP}$ & MO & 17-May-95 & $8: 34 \mathrm{AM}$ & $\mathrm{CST}$ & 37.833 & -94.500 & 22.4 & \\
\hline $\mathrm{SPC}+\mathrm{THP}$ & $\mathrm{MS} / \mathrm{AL}$ & 10-Jan-08 & 2:13 PM & $\mathrm{CST}$ & 33.417 & -88.183 & 22.4 & \\
\hline $\mathrm{SPC}+\mathrm{THP}$ & GA & $14-F e b-00$ & $12: 49 \mathrm{AM}$ & EST & 31.067 & -84.083 & 24.0 & \\
\hline $\mathrm{SPC}+\mathrm{THP}$ & $\mathrm{AL}$ & 23-Jan-12 & 3:58 AM & $\mathrm{CST}$ & 33.700 & -86.800 & 24.9 & \\
\hline $\mathrm{SPC}+\mathrm{THP}$ & $\mathrm{FL}$ & 2-Feb-07 & $3: 10 \mathrm{AM}$ & EST & 28.883 & -82.050 & 26.1 & \\
\hline $\mathrm{SPC}+\mathrm{THP}$ & $\mathrm{PA}$ & 31-May-98 & 7:20 PM & EST & 41.217 & -74.867 & 32.0 & \\
\hline SPC+THP & IN & 18 -Oct-07 & 9:18 PM & EST & 41.267 & -85.600 & 32.0 & \\
\hline $\mathrm{SPC}+\mathrm{THP}$ & $\mathrm{AR}$ & 31-Dec-10 & 6:05 AM & $\mathrm{CST}$ & 35.983 & -94.567 & 34.0 & \\
\hline $\mathrm{SPC}+\mathrm{THP}$ & MO & 29-Feb-12 & 4:00 AM & $\mathrm{CST}$ & 36.900 & -90.217 & 34.0 & \\
\hline $\mathrm{SPC}+\mathrm{THP}$ & GA & 30-Jan-13 & 11:12 AM & EST & 34.333 & -84.950 & 35.1 & \\
\hline $\mathrm{SPC}+\mathrm{THP}$ & $\mathrm{TX}$ & 7-May-95 & 3:10 PM & CST & 33.767 & -97.333 & 41.6 & \\
\hline $\mathrm{SPC}+\mathrm{THP}$ & FL & 2-Feb-07 & 3:37 AM & EST & 28.967 & -81.583 & 42.0 & \\
\hline $\mathrm{SPC}+\mathrm{THP}$ & MO & 7-Jan-08 & 6:29 PM & CST & 37.167 & -93.067 & 42.0 & \\
\hline $\mathrm{SPC}+\mathrm{THP}$ & WI & 18-Jun-01 & 7:06 PM & $\mathrm{CST}$ & 45.783 & -92.733 & 48.3 & \\
\hline $\mathrm{SPC}+\mathrm{THP}$ & NY & 31-May-98 & $3: 22$ PM & EST & 42.933 & -73.800 & 48.8 & \\
\hline $\mathrm{SPC}+\mathrm{THP}$ & MO & 31-May-13 & 7:50 PM & CDT & 38.683 & -90.750 & 52.3 & \\
\hline $\mathrm{SPC}+\mathrm{THP}$ & MA & 1-Jun-11 & 3:17 PM & EST & 42.067 & -72.450 & 60.0 & \\
\hline $\mathrm{SPC}+\mathrm{THP}$ & $\mathrm{KS}$ & 10-May-10 & 2:43 PM & $\mathrm{CST}$ & 36.867 & -97.817 & 66.0 & \\
\hline $\mathrm{SPC}+\mathrm{THP}$ & IL & 9-May-95 & 4:22 PM & CST & 39.783 & -89.650 & 80.0 & \\
\hline $\mathrm{SPC}+\mathrm{THP}$ & MS & 25-Dec-12 & $3: 20 \mathrm{PM}$ & CST & 30.650 & -89.683 & 97.2 & \\
\hline $\mathrm{SPC}+\mathrm{THP}$ & NY & 31-May-98 & 4:30 PM & EST & 42.067 & -76.150 & 99.2 & \\
\hline $\mathrm{SPC}+\mathrm{THP}$ & MO & 11-Apr-01 & $10: 30 \mathrm{AM}$ & $\mathrm{CST}$ & 40.400 & -94.317 & 122.4 & \\
\hline \multicolumn{9}{|c|}{ F4 intensity class } \\
\hline $\mathrm{SPC}+\mathrm{THP}$ & $\mathrm{TX}$ & 15-May-13 & 7:06 PM & CST & 32.383 & -97.733 & 4.4 & \\
\hline $\mathrm{PE}$ & $\mathrm{CT}$ & 10-Jul-89 & 4:30 PM & EST & 41.317 & -72.933 & 5.0 & \\
\hline $\mathrm{PE}$ & KS & 15-Jun-92 & 6:30 PM & CST & 39.450 & -98.217 & 5.0 & \\
\hline PE & OK & 26-Apr-91 & $8: 45$ PM & CST & 36.450 & -95.700 & 6.0 & \\
\hline $\mathrm{SPC}+\mathrm{THP}$ & AR & 15-Apr-98 & 1:50 AM & $\mathrm{CST}$ & 35.883 & -90.167 & 8.0 & $\mathrm{X}$ \\
\hline $\mathrm{SPC}+\mathrm{THP}$ & $\mathrm{TX}$ & 27-May-97 & 3:50 PM & $\mathrm{CST}$ & 30.283 & -97.800 & 9.0 & \\
\hline $\mathrm{SPC}+\mathrm{THP}$ & TX & 25-Apr-94 & 8:30 PM & CST & 32.600 & -96.767 & 9.6 & \\
\hline $\mathrm{SPC}+\mathrm{THP}$ & $\mathrm{MX} / \mathrm{TX}$ & 24-Apr-07 & 5:30 PM & CST & 28.417 & -100.317 & 10.0 & \\
\hline PE & $\mathrm{MN}$ & 16-Jun-92 & 4:18 PM & CST & 44.033 & -95.817 & 11.0 & $X$ \\
\hline $\mathrm{SPC}+\mathrm{THP}$ & MA & 29-May-95 & 6:07 PM & EST & 42.200 & -73.367 & 12.0 & \\
\hline SPC+THP & MD & 2-Jun-98 & 8:43 PM & EST & 39.650 & -78.933 & 13.0 & \\
\hline
\end{tabular}




\begin{tabular}{|c|c|c|c|c|c|c|c|c|}
\hline Source & $\begin{array}{l}\text { U.S. States } \\
\text { or Country }\end{array}$ & Date & TD time & $\begin{array}{l}\text { Time } \\
\text { zone }\end{array}$ & $\begin{array}{l}\text { TD Lat } \\
\left({ }^{\circ}\right)\end{array}$ & $\begin{array}{l}\text { TD Lon } \\
\left({ }^{\circ}\right)\end{array}$ & $\begin{array}{c}\text { Path } \\
\text { length } \\
(\mathbf{k m})\end{array}$ & Outbreak \\
\hline $\mathrm{SPC}+\mathrm{THP}$ & $\mathrm{KS}$ & 28-May-13 & 5:39 PM & CDT & 39.050 & -97.717 & 15.3 & \\
\hline $\mathrm{SPC}+\mathrm{THP}$ & KY & 2-Mar-12 & 4:23 PM & EST & 38.783 & -84.633 & 15.9 & \\
\hline $\mathrm{PE}$ & TX & $25-A p r-90$ & $3: 44$ PM & CST & 33.050 & -96.617 & 16.0 & \\
\hline PE & MO & 29-Nov-91 & 6:05 PM & CST & 37.050 & -93.300 & 16.0 & \\
\hline $\mathrm{PE}$ & OK & 11-May-92 & 3:00 PM & CST & 34.717 & -95.850 & 16.0 & \\
\hline $\mathrm{SPC}+\mathrm{THP}$ & $\mathrm{AL}$ & 1-Mar-07 & 1:08 PM & CST & 31.283 & -85.917 & 16.0 & \\
\hline PE & IA & 31-May-89 & 6:50 PM & CST & 42.433 & -93.183 & 18.0 & \\
\hline PE & $\mathrm{IN}$ & 2-Jun-90 & 7:50 PM & EST & 39.833 & -86.033 & 18.0 & \\
\hline $\mathrm{SPC}+\mathrm{THP}$ & VA & 6-Aug-93 & $12: 30 \mathrm{PM}$ & EST & 37.200 & -77.400 & 19.6 & \\
\hline PE & IL & 2-Jun-90 & 5:07 PM & CST & 39.067 & -88.083 & 20.0 & \\
\hline PE & $\mathrm{NC}$ & 5-May-89 & 7:01 PM & EST & 34.933 & -80.550 & 21.0 & \\
\hline PE & $\mathrm{KS}$ & 26-Mar-91 & 6:45 PM & CST & 37.967 & -98.050 & 21.0 & \\
\hline PE & $\mathrm{NC}$ & 5-May-89 & 5:54 PM & EST & 35.733 & -80.683 & 22.0 & \\
\hline $\mathrm{SPC}+\mathrm{THP}$ & IN & 26-Apr-94 & 11:58 PM & EST & 40.450 & -86.917 & 22.4 & \\
\hline $\mathrm{CA}$ & SD & 30-Мау-98 & 7:26 PM & CST & 43.733 & -97.600 & 22.5 & \\
\hline PE & $\mathrm{SC}$ & 5-May-89 & 5:20 PM & EST & 34.950 & -81.933 & 24.0 & \\
\hline $\mathrm{SPC}+\mathrm{THP}$ & OK & 3-May-99 & 8:10 PM & CST & 35.933 & -97.950 & 24.0 & $\mathrm{X}$ \\
\hline PE & $\mathrm{TX}$ & 16-Мay-89 & 11:08 PM & CST & 29.300 & -100.350 & 27.0 & \\
\hline $\mathrm{SPC}+\mathrm{THP}$ & $\mathrm{AL}$ & 16-Dec-00 & 11:54 AM & CST & 33.200 & -87.533 & 28.8 & \\
\hline PE & $\mathrm{IN}$ & 2-Jun-90 & 8:20 PM & EST & 38.883 & -86.050 & 29.0 & \\
\hline $\mathrm{SPC}+\mathrm{THP}$ & $\mathrm{AL}$ & 1-Mar-07 & $12: 27 \mathrm{PM}$ & CST & 32.117 & -87.417 & 29.5 & \\
\hline PE & $\mathrm{AL}$ & 15-Nov-89 & 4:30 PM & CST & 34.700 & -86.750 & 30.0 & \\
\hline $\mathrm{PE}$ & IA & 13-Mar-90 & 4:53 PM & CST & 42.067 & -91.683 & 30.0 & $\mathrm{X}$ \\
\hline $\mathrm{SPC}+\mathrm{THP}$ & $\mathrm{NE}$ & 4-Oct-13 & 5:12 PM & CDT & 42.133 & -97.083 & 31.0 & \\
\hline PE & MS & 9-Mar-92 & 9:40 PM & CST & 33.000 & -90.833 & 32.0 & \\
\hline PE & $\mathrm{TX}$ & 27-Jun-92 & 6:31 PM & CST & 32.650 & -96.717 & 32.0 & \\
\hline PE & $\mathrm{TX}$ & 21-Nov-92 & $3: 27 \mathrm{PM}$ & CST & 29.783 & -95.317 & 32.0 & \\
\hline $\mathrm{SPC}+\mathrm{THP}$ & OK & 19-Мay-13 & 6:00 PM & CDT & 35.250 & -97.150 & 32.0 & \\
\hline $\mathrm{SPC}+\mathrm{THP}$ & $\mathrm{KS}$ & 4-May-03 & 3:18 PM & CST & 39.067 & -94.833 & 33.6 & $\mathrm{X}$ \\
\hline PE & IL & 7-Jan-89 & 5:19 PM & CST & 38.417 & -87.817 & 35.0 & \\
\hline PE & $\mathrm{TX}$ & 1-Jun-90 & 4:20 PM & CST & 31.417 & -103.500 & 35.0 & \\
\hline $\mathrm{SPC}+\mathrm{THP}$ & OK & 10-May-10 & 4:32 PM & CST & 35.200 & -97.417 & 35.0 & \\
\hline $\mathrm{SPC}+\mathrm{THP}$ & MS & 10-Feb-13 & 5:03 PM & CST & 31.183 & -89.183 & 36.2 & \\
\hline PE & IL & 2-Jun-90 & 4:45 PM & CST & 41.950 & -88.250 & 37.0 & \\
\hline $\mathrm{SPC}+\mathrm{THP}$ & $\mathrm{TN}$ & 10-Apr-09 & 11:19 AM & CST & 35.850 & -86.417 & 37.5 & \\
\hline $\mathrm{SPC}+\mathrm{THP}$ & OK & 10-May-10 & 4:20 PM & CST & 35.317 & -97.517 & 38.0 & \\
\hline $\mathrm{SPC}+\mathrm{THP}$ & $\mathrm{KS}$ & 3-May-99 & 7:13 PM & CST & 37.317 & -97.400 & 39.0 & $\mathrm{X}$ \\
\hline PE & GA & 22-Nov-92 & 11:44 AM & EST & 33.900 & -84.567 & 41.0 & \\
\hline $\mathrm{SPC}+\mathrm{THP}$ & $\mathrm{IL}$ & 29-Feb-12 & 4:51 AM & CST & 37.733 & -88.550 & 42.6 & \\
\hline PE & KY & 22-Nov-92 & 4:52 PM & EST & 38.667 & -85.067 & 43.0 & \\
\hline PE & $\mathrm{NE}$ & 15-Jun-90 & 6:00 PM & CST & 40.183 & -101.067 & 45.0 & \\
\hline $\mathrm{SPC}+\mathrm{THP}$ & KS & 28-Feb-07 & 7:24 PM & CST & 38.133 & -95.100 & 45.0 & \\
\hline $\mathrm{SPC}+\mathrm{THP}$ & $\mathrm{AR}$ & 21-Jan-99 & 4:45 PM & CST & 36.317 & -90.600 & 46.0 & \\
\hline $\mathrm{SPC}+\mathrm{THP}$ & $\mathrm{TN}$ & 18-May-95 & 3:52 PM & CST & 35.033 & -87.500 & 46.4 & \\
\hline $\mathrm{PE}$ & $\mathrm{OK}$ & 26-Apr-91 & $7: 10 \mathrm{PM}$ & CST & 36.300 & -96.700 & 51.0 & \\
\hline PE & GA & 22-Nov-92 & 4:45 PM & EST & 33.317 & -83.383 & 51.0 & \\
\hline
\end{tabular}




\begin{tabular}{|c|c|c|c|c|c|c|c|c|}
\hline Source & $\begin{array}{l}\text { U.S. States } \\
\text { or Country }\end{array}$ & Date & TD time & $\begin{array}{l}\text { Time } \\
\text { zone }\end{array}$ & $\begin{array}{l}\text { TD Lat } \\
\left({ }^{\circ}\right)\end{array}$ & $\begin{array}{c}\text { TD Lon } \\
\left({ }^{\circ}\right)\end{array}$ & $\begin{array}{l}\text { Path } \\
\text { length } \\
(\mathbf{k m})\end{array}$ & Outbreak \\
\hline $\mathrm{PE}$ & IN & 2-Jun-90 & 10:00 PM & EST & 39.217 & -84.850 & 53.0 & \\
\hline SPC+THP & OK & 10-Feb-09 & 6:48 PM & $\mathrm{CST}$ & 33.567 & -97.350 & 56.0 & $\mathrm{X}$ \\
\hline $\mathrm{SPC}+\mathrm{THP}$ & OK & 3-May-99 & $8: 25$ PM & CST & 35.883 & -97.683 & 63.0 & $X$ \\
\hline PE & MS & $22-$ Nov-92 & 12:14 AM & CST & 31.867 & -89.550 & 64.0 & \\
\hline $\mathrm{SPC}+\mathrm{THP}$ & $\mathrm{KS}$ & 14-Apr-12 & 4:32 PM & CST & 38.467 & -98.083 & 65.8 & \\
\hline $\mathrm{PE}$ & NY & 10-Jul-89 & $1: 27 \mathrm{PM}$ & EST & 41.533 & -74.233 & 68.0 & \\
\hline $\mathrm{SPC}+\mathrm{THP}$ & $\mathrm{AL}$ & 27-Mar-94 & 10:55 AM & $\mathrm{CST}$ & 33.733 & -86.133 & 76.0 & \\
\hline $\mathrm{SPC}+\mathrm{THP}$ & $\mathrm{AR}$ & 24-May-11 & 11:10 PM & CST & 35.450 & -93.767 & 76.0 & \\
\hline $\mathrm{PE}$ & IA & 24-May-89 & 5:11 PM & CST & 41.067 & -94.683 & 79.0 & \\
\hline $\mathrm{SPC}+\mathrm{THP}$ & IN/KY & 2-Mar-12 & 2:50 PM & EST & 38.433 & -86.183 & 79.0 & \\
\hline SPC+THP & IL & 13-May-95 & 3:18 PM & CST & 40.617 & -91.283 & 80.0 & \\
\hline SPC+THP & $\mathrm{OH}$ & 10 -Nov-02 & $2: 15 \mathrm{PM}$ & CDT & 40.783 & -84.767 & 84.5 & \\
\hline PE & IA & 24-Мау-89 & 5:20 PM & $\mathrm{CST}$ & 41.167 & -92.900 & 106.0 & \\
\hline PE & OK & 26-Apr-91 & 5:30 PM & CST & 36.300 & -96.417 & 106.0 & \\
\hline $\mathrm{SPC}+\mathrm{THP}$ & MN & 29-Mar-98 & 3:50 PM & CST & 43.950 & -95.567 & 108.0 & \\
\hline PE & IL & 2-Jun-90 & 5:20 PM & CST & 40.400 & -91.333 & 170.0 & \\
\hline $\mathrm{SPC}+\mathrm{THP}$ & $\mathrm{AR}$ & 5-Feb-08 & 4:50 PM & CST & 35.067 & -93.100 & 196.0 & \\
\hline PE & $\mathrm{NE}$ & 13-Mar-90 & 5:05 PM & CST & 40.233 & -98.567 & 198.0 & $\mathrm{X}$ \\
\hline PE & MS & 21-Nov-92 & 11:27 PM & CST & 31.900 & -90.367 & 206.0 & \\
\hline \multicolumn{9}{|c|}{ F5 intensity class } \\
\hline $\mathrm{SPC}+\mathrm{THP}$ & $\begin{array}{l}\text { Manitoba } \\
\text { (Canada) }\end{array}$ & 22-Jun-07 & 6:30 PM & CDT & 49.900 & -97.800 & 6.0 & \\
\hline $\mathrm{SPC}+\mathrm{THP}$ & TX & 27-May-97 & $2: 40 \mathrm{PM}$ & CST & 30.833 & -97.600 & 8.2 & \\
\hline $\mathrm{SPC}+\mathrm{THP}$ & WI & 18-Jul-96 & 6:05 PM & CST & 43.683 & -88.583 & 21.3 & $\mathrm{X}$ \\
\hline $\mathrm{PE}+\mathrm{SE}$ & IL & 28-Aug-90 & $2: 15 \mathrm{PM}$ & $\mathrm{CST}$ & 41.550 & -88.433 & 26.0 & $\mathrm{X}$ \\
\hline PE & MN & 16-Jun-92 & 4:00 PM & CST & 43.717 & -95.817 & 26.0 & $\mathrm{X}$ \\
\hline $\mathrm{SPC}+\mathrm{THP}$ & OK & 31-May-13 & 6:03 PM & $\mathrm{CDT}$ & 35.533 & -97.950 & 26.1 & \\
\hline $\mathrm{SPC}+\mathrm{THP}$ & OK & 20-May-13 & 2:56 PM & $\mathrm{CDT}$ & 35.267 & -97.417 & 27.0 & \\
\hline $\mathrm{SPC}+\mathrm{THP}$ & KS & 13-Mar-90 & 5:30 PM & CST & 38.150 & -97.433 & 35.0 & $\mathrm{X}$ \\
\hline $\mathrm{SPC}+\mathrm{THP}$ & KS & 4-May-07 & 8:20 PM & CST & 37.367 & -99.167 & 35.0 & \\
\hline $\mathrm{SPC}+\mathrm{THP}$ & MO & 22-May-11 & 4:34 PM & CST & 37.083 & -94.517 & 35.6 & $\mathrm{X}$ \\
\hline $\mathrm{SPC}+\mathrm{THP}$ & MS & 27-Apr-11 & 1:30 PM & $\mathrm{CST}$ & 32.933 & -88.867 & 47.0 & $X$ \\
\hline $\mathrm{SPC}+\mathrm{THP}$ & MS & 27-Apr-11 & 2:42 PM & CST & 34.050 & -88.417 & 60.0 & $\mathrm{X}$ \\
\hline $\mathrm{SPC}+\mathrm{THP}$ & $\mathrm{AL}$ & 27-Apr-11 & 5:19 PM & CST & 34.450 & -85.900 & 60.0 & $\mathrm{X}$ \\
\hline SPC+THP & OK & 3-May-99 & 5:23 PM & CST & 35.133 & -97.850 & 61.0 & $\mathrm{X}$ \\
\hline $\mathrm{SPC}+\mathrm{THP}$ & IA & 25-May-08 & 3:48 PM & $\mathrm{CST}$ & 42.567 & -92.783 & 69.0 & \\
\hline PE & $\mathrm{KS}$ & 26-Apr-91 & 4:57 PM & CST & 37.867 & -96.833 & 74.0 & \\
\hline $\mathrm{SPC}+\mathrm{THP}$ & $\mathrm{AL}$ & 8-Apr-98 & 6:01 PM & CST & 33.283 & -87.833 & 80.0 & $\mathrm{X}$ \\
\hline $\mathrm{SPC}+\mathrm{THP}$ & $\mathrm{TN}$ & 16-Apr-98 & 3:50 PM & $\mathrm{CST}$ & 35.283 & -87.550 & 80.0 & $\mathrm{X}$ \\
\hline $\mathrm{SPC}+\mathrm{THP}$ & OK & 24-May-11 & 2:50 PM & $\mathrm{CST}$ & 35.567 & -97.967 & 105.0 & \\
\hline $\mathrm{PE}$ & KS & 13-Mar-90 & 4:34 PM & CST & 38.000 & -97.350 & 112.0 & $\mathrm{X}$ \\
\hline $\mathrm{SPC}+\mathrm{THP}$ & $\mathrm{AL}$ & 27-Apr-11 & 2:05 PM & CST & 34.083 & -88.133 & 212.6 & $X$ \\
\hline
\end{tabular}


In order to perform a more detailed and robust analysis of the hypothesized link between the tornadoes and the global anisotropy of the physical space, a further database concerning eleven tornado outbreaks occurred in the period 1990-2011 was built, including all the events occurred in each outbreak and covering different months, seasons and times of the day. All the tornado outbreaks hit the U.S.A. with one of them, occurred on August 28, 1990, extended to Ontario, Canada; all outbreaks cover a portion of a single day but two of them that covered two consecutive days, as well as they include at least one F5 tornado but two of them where the strongest tornadoes were F4. The considered tornado outbreaks span the months of February, March, April, May, June, July, August which fall into three of the seasons, as well as single tornado events occur practically every time of the day and at any latitude between about $30^{\circ} \mathrm{N}$ and $50^{\circ} \mathrm{N}$.

All in all, 434 tornadoes populate the second database, with 100 tornadoes classified as F0, 150 events classified as F1, 92 tornadoes in the F2 class, 57 in the F3 class, 22 violent $\mathrm{F} 4$ tornadoes and 13 catastrophic $\mathrm{F} 5$ events.

Table2 lists the above mentioned 11 tornado outbreaks.

Table2. Tornado outbreaks used to build Fig.6(a-v) in Section 4. For any outbreak, the number of tornadoes in each intensity class from F0 to F5 is indicated. The data are extracted from the SPC [18] and THP [19]databases of tornado events.

\begin{tabular}{|c|c|c|c|c|c|c|c|}
\hline Date & U.S. States or Country & Nr. of Fo & Nr. of F1 & Nr. of F2 & Nr. of F3 & Nr. of F4 & Nr. of F5 \\
\hline March 13, 1990 & IA, KS, MO, NE, OK, TX & 10 & 20 & 13 & 10 & 2 & 2 \\
\hline August 28, 1990 & IL, MI, NY, Ontario (Canada) & 4 & 4 & 2 & 1 & 0 & 1 \\
\hline June 16,1992 & IA, MN, NE, ND, SD & 15 & 15 & 21 & 10 & 1 & 1 \\
\hline July 18,1996 & WI & 6 & 2 & 1 & 0 & 0 & 1 \\
\hline April 8, 1998 & AL, AR, GA, LA, TN, TX & 4 & 5 & 3 & 1 & 0 & 1 \\
\hline April 15-16, 1998 & $\mathrm{AL}, \mathrm{AR}, \mathrm{GA}, \mathrm{IL}, \mathrm{IN}, \mathrm{KY}, \mathrm{MI}, \mathrm{MS}, \mathrm{MO}, \mathrm{TN}$ & 24 & 15 & 12 & 7 & 1 & 1 \\
\hline May 03, 1999 & $\mathrm{KS}, \mathrm{OK}$ & 9 & 12 & 7 & 6 & 3 & 1 \\
\hline May 04,2003 & AR, IL, KS, KY, MO, OK, TN & 9 & 23 & 11 & 9 & 6 & 0 \\
\hline February 10-11, 2009 & AR, MO, OK, TN, TX & 3 & 9 & 1 & 0 & 1 & 0 \\
\hline April 27, 2011 & $\mathrm{AL}, \mathrm{MS}$ & 14 & 39 & 17 & 13 & 8 & 4 \\
\hline May 22, 2011 & AR, IL, IA, KS, MO, OK & 2 & 6 & 4 & 0 & 0 & 1 \\
\hline
\end{tabular}

\section{Theoretical Insights}

\subsection{The Global Anisotropy of the Physical Space and the Byuon Theory}

$\operatorname{In}[20,21]$ the earliest experiments are described where a fundamental anisotropy of the physical space as well as a new non-gauge interaction, different from the four known ones (strong, weak, electromagnetic, and gravitational), were first detected. Besides the lack of gauge invariance, an important feature of this new interaction is just its anisotropy that arises in a wide range of sizes, from the weak interactions, i.e. $10^{-19} \mathrm{~m}[22]$, up to the size of our Galaxy, i.e. $10^{21} \mathrm{~m}$ [23], and more[24].

The physical nature of the new force is explained by the byuon theory, a non-gauge theory of the formation of the physical space and the world of elementary particles from some unobservable objects called "byuons"[25-27].

According to the byuon theory [32] the potentials of physical fields can act upon the process of mass formation of the elementary particles because a fraction of such mass, associated with the formation of their inner space, is proportional to the modulus of a summary potential $A_{\Sigma}$, i.e. thesum of the potentials of all known force fields calculated using the energy relationexpressed by Eq. (3.1.) in Baurov and Malov[28]. Such summary potential cannot exceed, by magnitude, the modulus of the cosmological vectorial potential $\mathrm{A}_{\mathrm{g}}$, a new fundamental constanthaving absolute value $\left|\mathbf{A}_{\mathbf{g}}\right| \approx 1.9 \cdot 10^{5} \mathrm{~T} \cdot \mathrm{m}$.

As the result of the action of the field potentials (decreasing $\left|\mathbf{A}_{\Sigma}\right|$ ), each particle gains an energy $\Delta m \cdot c^{2}$ that corresponds to a new force of nature throwing substance out of the region with the weakened $A_{\Sigma}$. Experimental investigations with the use of gravimeters and magnets and plasma systems[29], as well as the measurements of changes in the $\beta$-decay rate of radioactive elements[22,30], that were later confirmed by independent researches [31], have shown that the substance is ejected from the region with the weakened $A_{\Sigma}$ along a cone with an angular opening about $100^{\circ}$ around the vector $A_{g}$ determining the global anisotropy of the physical space and having the following astronomical coordinates in the second equatorial system: $\alpha \approx 293^{\circ} \pm 10^{\circ}, \delta \approx 36^{\circ} \pm 10^{\circ}$, where $\alpha$ is the right ascension and $\delta$ is the declination.

Fig. 1shows the direction of the cosmological vector potential $A_{g}$ projected onto the Earth's orbital plane, representing the direction of the global anisotropy of the physical space. 


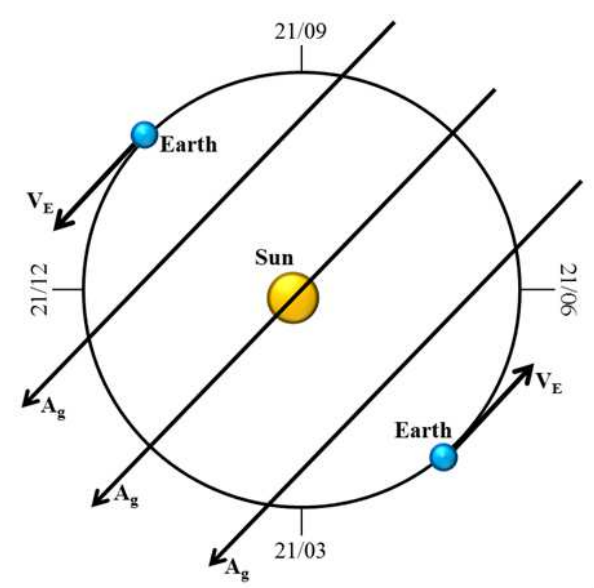

Fig. 1. Projection of the cosmological vector potential $A_{g}$ onto a simplified Earth's orbital plane; $V_{E}$ is the Earth's instantaneous velocity vector.

The analysis of a long run of experiments has shown that the new force has a nonlinear and nonlocal character and can be represented as a complex series in terms of changes of the summary potential $A_{\Sigma}$ as per Eq.(4) in Baurov [21]. The first term of the series is the following:

$$
F=2 N m_{v} c^{2} \lambda_{1}^{2} \Delta A_{\Sigma}\left[\Delta\left(\Delta A_{\Sigma}\right) / \Delta x\right]
$$

where $N$ is the number of stable particles (electrons, protons, and neutrons) in the test body, $\Delta A_{\Sigma}$ is the difference in changes of the summary potential $A_{\Sigma}$ at the location points of a test body and sensor element, $\Delta\left(\Delta A_{\Sigma}\right) / \Delta x$ is the gradient in space of the difference potentials $\Delta A_{\Sigma} ; x$ is the length of an arc of a circle for experiments with solenoids, therefore a space coordinate; $2 m_{v} c^{2}=33 \mathrm{eV} ; \lambda_{1}=10^{-6}(\mathrm{~T} \mathrm{~m})^{-1}$ is the first coefficient of the series.

The fundamental research of the global anisotropy of physical spacealong with the basics of the byuon theory based upon such anisotropy is summarized in Baurov[32] which includes all the relevant bibliography.

The revealed anisotropic properties of the physical space were found to affect as well very powerful geophysical processes such as the strongest earthquakes, offering a chance for a deeper understanding and even a reference framework for a possible prediction in future [33].

The following few consequences of the byuon theory are most important in the context of this article:

- Extremely high magnitude magnetic vector potentials having a large component anticollinear with respect to the cosmological vector potential $A_{g}$ can effectively weaken the summary potential $\mathrm{A}_{\Sigma}$, resulting in an acceleration of the surrounding substance along a conical path[32].

- The potential of the Earth's gravitational field is always negative and decreases in absolute value with height from the local surface, therefore as per Eq. (1) a particle rising from the surface with high enough speed, experiencing a substantial rate of decrease of the gravitational potential, is subjected to an upward force towards higher values of the summary potential $\mathrm{A}_{\Sigma}$.

- Quantum states of the byuons interact in regions of weakened summary potential to minimize their potential energy, creating the fundamental onedimensional physical space along with rotation of the material substance around an axis perpendicular to the cosmological vector potential $A_{g}$, which arises from the residues of such minimization [27].

- More precisely, most of the residual potential energy of interaction of byuons in the fundamental one-dimensional space created by the byuons themselves converts into the spin of primary particles, such as the electron, any lepton, etc., as well as into its mass; according to the byuon theory, any natural rotation such as the rotation of planets, stars, galaxies and the expected rotation of the Universe, arises from this mechanism of minimization of the potential energy of interaction of byuons [27].

- The energy of the rotational motion of particles on the boundary of an object having characteristic size on the order of $10 \mathrm{~cm}$ can be substantially enhanced by the coupling of such particles through the quantum information channel predicted by the byuon theory $[25,26]$.

\subsection{Tornadoes and the Global Anisotropy of the Physical Space}

Whatever the processed leading to the onset of a tornado, afterwards itcan further accumulate energy along its path by means of well understood processes[2,3]; two further concurrent processes are proposed here, which are thought to sustain or reinforce a tornado during its development.

The first process stems from the consideration, already expressed in Section 3.1., that the reduction of the summary potential $A_{\Sigma}$ by means of the Earth's gravitational potential, that is always negative, is stronger near the Earth's surface than at any height along the local vertical axis; therefore, according to Eq. (1) the flow in an updraft is further accelerated at the expense of the gravitational potential in the direction of the increasing summary potential, which coincides with the direction to the local zenith.

Such process appears similar to the one described in [26,34]: during the motion of a liquid substancepowered by a centrifugal pump, in a closed circuit having ascending and descending sections (height of about $2.6 \mathrm{~m}$ ), additional energy is released at the level of $15-20 \%$, which can't be explained from the perspective of standard calibrated physical models. Of course, the stronger the updraft, the greater the acceleration because the uprising particles experience a faster change (decrease) of the summary potential.

The second process is likely even more important and specific to tornadoes. Recalling Section 3.1., any natural rotation arises from the mechanism of minimization of the potential energy of interaction of byuons in their fundamental one-dimensional space [27]. 
The latter applies as well to a tornado that can gain a fraction of energy of its rotational motion from the minimization of the potential energy of interacting byuons in regions with summary potential weakened by means of the Earth's gravitational potential; provided that the cosmological vector potential lies around the horizontal plane tangent to the local Earth's surface, this process results in the generation of further rotation around the vertical axis of any particle while rising in the violent updraft associated to the tornado, thus further contributing to the energy and lifetime of the tornado itself.

Fig. 2 shows a very simplified scheme of the proposed processes contributing to the energy of a tornado system.

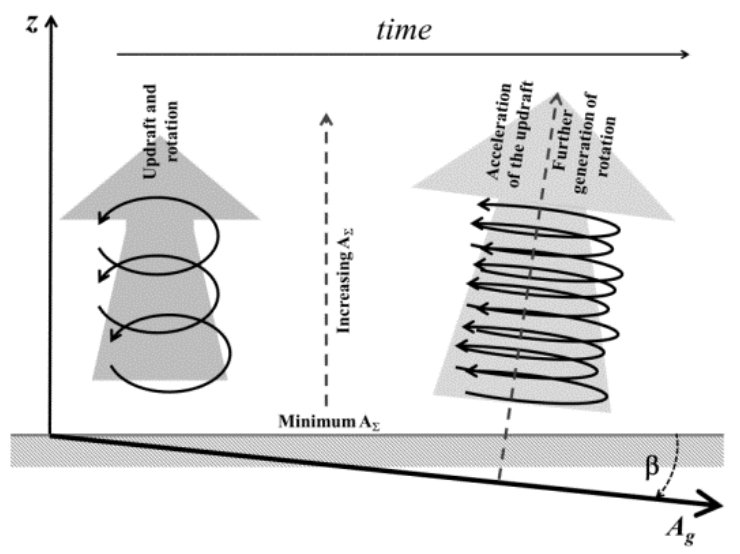

Fig. 2.Very simplified scheme of the proposed processes contributing to the energy of a tornado system: $A_{g}$ is the cosmological vector potential and $\beta$ is its altitude with regards to the local Earth's surface (shaded in the picture).

As a result, the new proposed mechanisms could help to discriminate situations favorable for the further accumulation of energy into a tornado and therefore its development into a high intensity and/or long lifetime or path system.

\subsection{From Lightning to Tornado}

In $[26,29,35]$ experiments are discussed where, if the magnetic vector potential of a discharge current of intensity up to $4 \mathrm{kA}$ is directed opposite to the vector $A_{g}$ at an optimal angle $\left(130^{\circ}-135^{\circ}\right)$, corresponding to the maximum action of the new force of nature, in the discharge can be released $20-40 \%$ more energy than that supplied by the power source; if the discharge currents are increased up to $200 \mathrm{kA}$, the situation can develop into an explosion, leading to the release of energy few orders of magnitude greater than the input energy.

On the basis of the above mentioned experiments as well as of the byuon theory, at least a fraction of the energy available for the onset of a tornado can be explained as the result of the vector of the lightning current, provided such current is high enough, which is collinear to the respective magnetic vector potential,lying on the reverse cone of action of the new force or at least having a component directed opposite the vector $A_{g}$ in order to weaken the summary potential $\mathrm{A}_{\Sigma}$, such additional energy coming from the process of formation of the masses of the particles in the discharge (electrons, etc.).

Considering a single cubic centimeter of the substance within the lightning discharge with current $100 \mathrm{kA}$, the value of $N$ will be equal to about $2 \cdot 10^{20} ; \Delta A_{\Sigma} \approx 10^{-2} \mathrm{~T} \mathrm{~m}$ and for each of the elementary particles (protons, neutrons) the factor $\Delta\left(\Delta A_{\Sigma}\right) / \Delta x$ can be assumed equal to the value of the magnetic field in the vicinity of the proton $\left(10^{12} \mathrm{~T}\right)$, as shown in Baurov et al.[22], therefore at the optimal arrangement of the vector potential of the discharge current with respect to the vector $A_{\mathrm{g}}$ (angle between the vectors $\approx 130^{\circ}$ ), it follows from Eq.(1) that a cubic centimeter of discharge will receive a new force having an intensity on the order of $10 \mathrm{~N}$. Considering that the mass of $1 \mathrm{~cm}^{3}$ of air is about $10^{-6} \mathrm{~kg}$, the obtained force will result in a huge acceleration on the order of $10^{7} \mathrm{~ms}^{-2}$.

It's known [36] that a lightning strike can travel at speeds around $150,000 \mathrm{~km} / \mathrm{s}$, therefore, assuming that its path length is between $2 \mathrm{~km}$ and $10 \mathrm{~km}$, its duration can be estimated in the range $10^{-5} \mathrm{~s}$ and $10^{-4} \mathrm{~s}$; furthermore, the average width of a lightning bolt is between $2.5 \mathrm{~cm}$ and $5 \mathrm{~cm}$, such width of course increasing with the lightning peak current. It could be noted as well that $10 \mathrm{~cm}$ is the order of magnitude of the distance a particle accelerated by the new force travels during $10^{-4} \mathrm{~s}$.

On the basis of the above it appears reasonable to assume that the approximately empty cavity (i.e., with vacuum inside) created as a result of an intense lightning explosion has a characteristic size on the order of $10 \mathrm{~cm}$, therefore activating the quantum information channelmentioned in Section3.1., and allowing the previously accelerated particles at the boundaries of the cavity to gain substantial energy in the form of rotational motion, in turn contributing to trigger the tornado.

Fig.3 shows a very simplified scheme of the proposed processes contributing to the onset of a tornado.

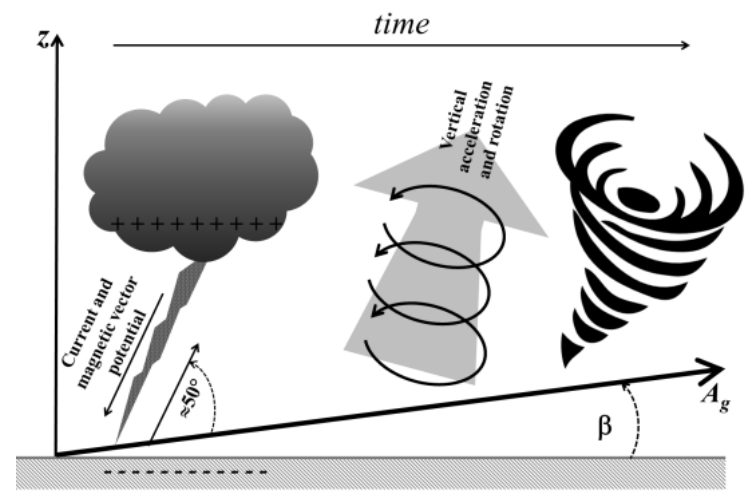

Fig. 3. Very simplified scheme of the proposed processes contributing to the onset of a tornado: $A_{g}$ is the cosmological vector potential and $\beta$ is its altitude with regards to the local Earth's surface (shaded in the picture); pluses and minuses indicate the cloud and surface electrostatic charges; the $+C G$ lightning below the cloud base is represented too.

The verification of the above described additional mechanism contributing to the onset of tornadoes starting from intense lightning flashes on the basis of observational evidence with real tornadoes is very difficult for few reasons.

A source of difficulty arises from the fact that the proposed mechanism is not deemed at allstrictly necessary 
for the onset of tornadoes but only a contributing process that sometimes can trigger tornadoes in otherwise less favorable atmospheric environments. Therefore, the fact that the onset of a tornado either allows or not for a role of the proposed mechanism doesn't speak about its reality.

Another source of difficulty lies in the fact that the tornadoes arise first at some elevation over the local terrain, i.e. inside the convective clouds, therefore the proposed mechanism can work both with cloud to ground (CG) and intra-cloud (IC) lightning flashes, the latter being hardly detected and characterized with regards to intensity, polarity, path by ground based lightning sensors. Additionally, the path is usually not available even for CG lightning.

Moreover, ground based lightning detection networks are mostly privately managed and the respective detailed data are confidential, including exact location, polarity and intensity, not to speak about the detailed path (if observed).

It is known[37] that positive lightning flashes (+CG), which are likely candidates for the activation of the proposed mechanism because they carry the highest peak currents, can follow very complex paths including long horizontal sections between convective and stratiform areas of the storm cloud system before delivering the positive charge to the ground. As a result, the only altitude of $A_{g}$ can't be sufficient to assess its angular deviation with regards to the lightning discharge and the associated magnetic vector potential in the three dimensional domain, its azimuth being needed too.

At least an extensive analysis of the local atmospheric environment supportive of tornadoes would be needed for any event, which is out of the scope of this article, as well as the observation of the intensity, polarity and possibly the paths of both CG and IC lightning would be required, at least for the most intense strikes, which could be available by means of new and future satellite sensors [38].

\section{Results and Discussion}

Only the processes proposed in Section 3.2., linking the evolution of the strongest tornadoes to the global anisotropy of the physical space,will be verified against observed data; as stated in Section 3.3., the verification of the processes allegedly linking the onset of tornadoes to very high peak current lightning discharges are deferred to a later time until the suitable data sets will be available.

Fig. 4 shows the average altitude of the cosmological vector potential $\mathrm{A}_{\mathrm{g}}$ during the lifetime of 139 tornadoes listed in Table 1. The data points are represented separately for each intensity class and, in each class, are arranged according to the increasing tornado path length.

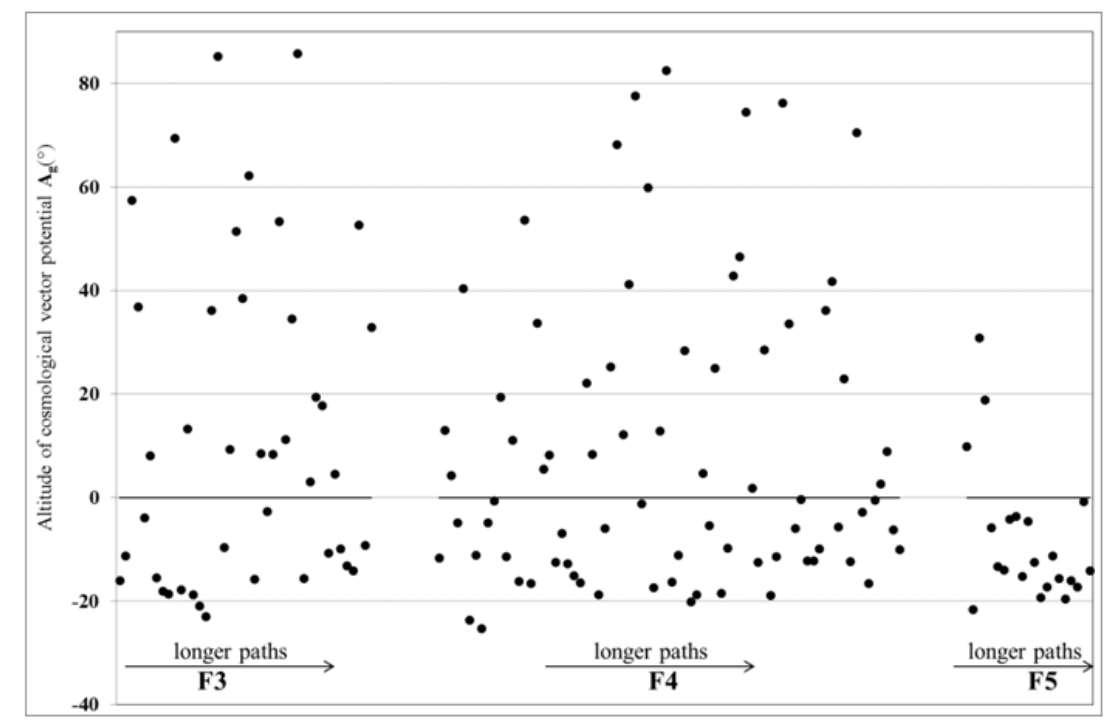

Fig. 4. Altitude of the cosmological vector $A_{g}$ during the lifetime of 139 tornadoes occurred in the period 1989-2013 and listed in Table 1; the data points belonging to the three most intense tornado classes (F3, F4, F5) are represented separately and in each class they are arranged according to increasing path lengths.

While no clear pattern arises for F3 tornadoes, with the F4 tornadoes the altitude of $\mathrm{A}_{\mathrm{g}}$ appears to concentrate in a range of $20^{\circ}$ on each side from the horizontal plane, with the spread clearly reducing with the increasing tornado pathlength and negative altitudes clearly prevailing. A striking evidence arises anyway with the most violent F5 tornadoes: for all the 21 events the altitude of $A_{g}$ is less than $30^{\circ}$ far from the horizontal plane, such angular distance reducing to less than $20^{\circ}$ with 18 out of 21 events, all such events occurring with a negative altitude.

Therefore, also recalling the relevance of the path length besides the intensity to characterize the tornado overall energy, as stated in Section 1 [7], it appears that the local altitude of the cosmological vector potential effectively discriminatesthe most powerful tornadoes.

A closer insight is provided with Fig.5(a) and Fig. 5(b), where the path lengths of the same tornado events represented in Fig. 4, limited to the classes F4 and F5, are shown against the altitude of the cosmological vector potential $\mathrm{A}_{\mathrm{g}}$.

For all the seven $\mathrm{F} 4$ events with path length greater than $90 \mathrm{~km}$ the altitude of $\mathrm{A}_{\mathrm{g}}$ lies within $20^{\circ}$ from the horizontal 
plane (Fig. 5a), and for six out of seven such events the maximum angular distance from horizontal reduces to $10^{\circ}$.

For all the fifteen out of twenty-one F5 events with path length greater than $26 \mathrm{~km}$ the altitude of $\mathrm{A}_{\mathrm{g}}$ lies in the range $-20^{\circ}$ to $0^{\circ}$ from the horizontal plane (Fig. $5 \mathrm{~b}$ ).

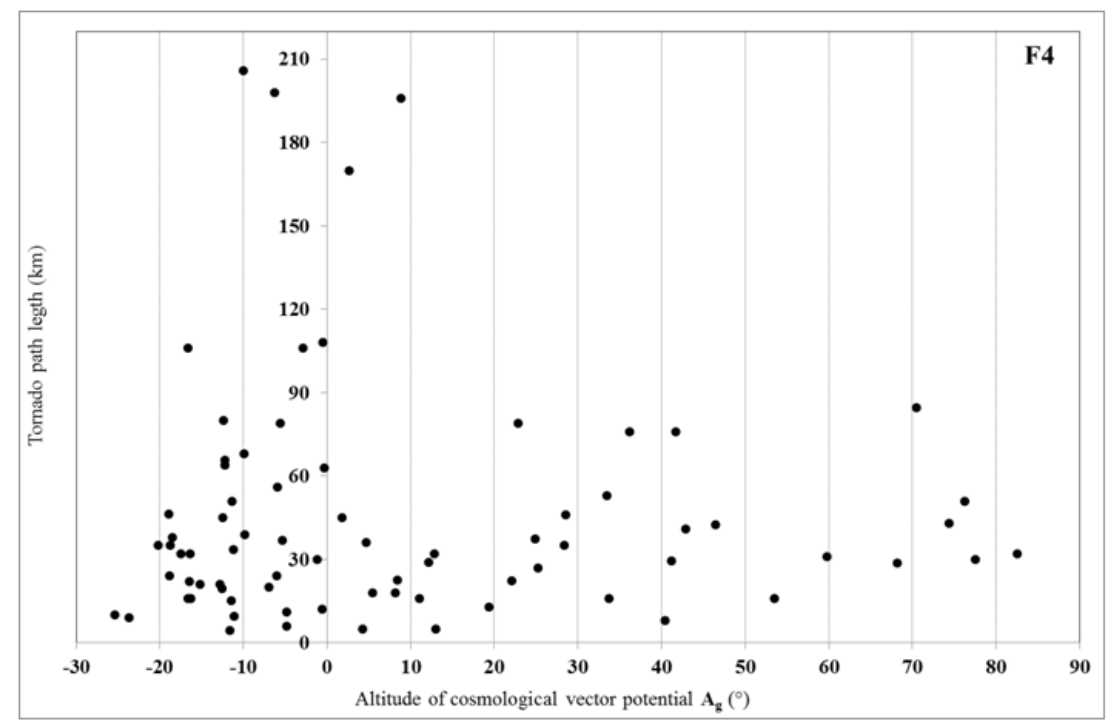

(a)

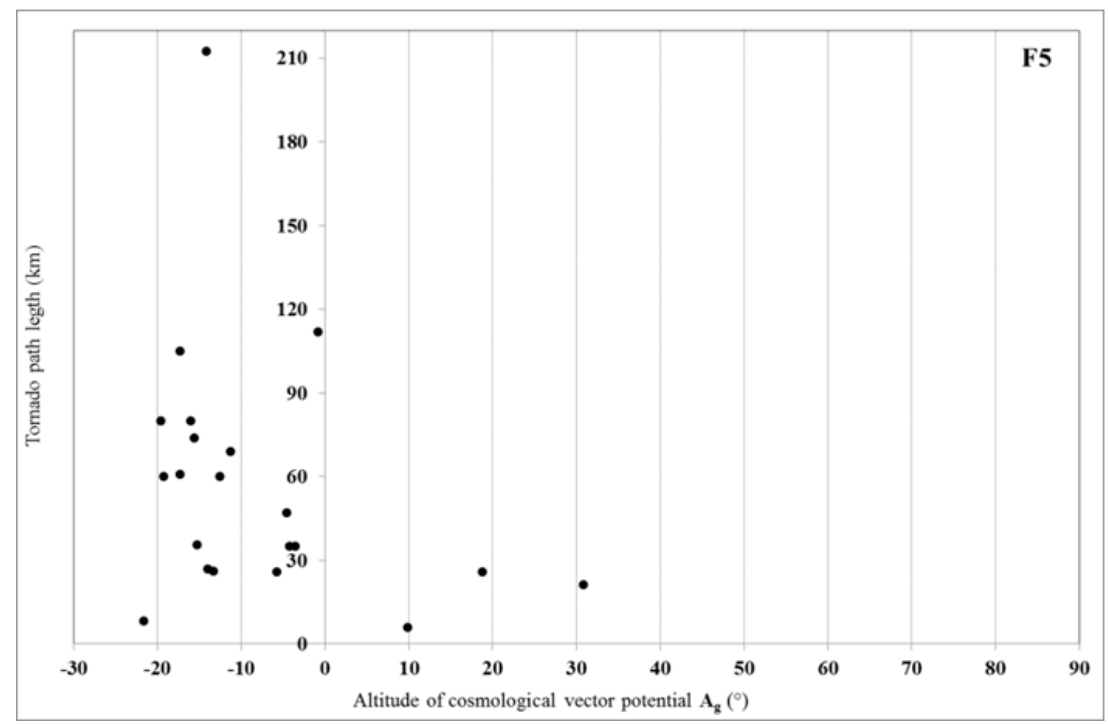

(b)

Fig. 5.Path lengths of tornadoes of intensity F4 (a) and F5 (b), occurred in the period 1989-2013, against the local altitude of the cosmological vector $A_{g}$.

The abovediscussed results support at least the general idea that the most energetic tornadoesare somehow connected with the global anisotropy of the physical space, which is an original conclusion of this article; here, the total energy of a tornado is meant as a combination of its maximum intensity in the Fujita scale and the length of its path. In the opinion of the authors, consistent clues are accumulating as well about the reality of the proposed mechanism contributing to the intensification of tornadoes.

In order to reduce the probability that the above evidence was obtained by chance, eleventornado outbreaks occurred in the period 1990-2011 and listed in Table 2 have been analyzed. In Fig. 6(a-v) two charts are shown for each considered outbreak, the first representing the intensity class of each tornado in the outbreak and the altitude of the cosmological vector potential $\mathrm{A}_{\mathrm{g}}$ at its touchdown along with the local solar time, the second representing the scatter diagram of the tornado intensity as well as of its path length against the altitude of $\mathrm{A}_{\mathrm{g}}$. It's noteworthy that here the altitude of $\mathrm{A}_{\mathrm{g}}$ at the tornado touchdown is computed instead of its average during the tornado lifetime as in Fig. 4, Fig. 5(a) and Fig. 5(b) because the lifetime was not always available for each tornado; this could introduce small errors especially with the longest lifetime events but the occurrence of such events just close to the minimum altitude prevents such errors to become significant.

The date of each tornado outbreak is indicated in the respective charts. 


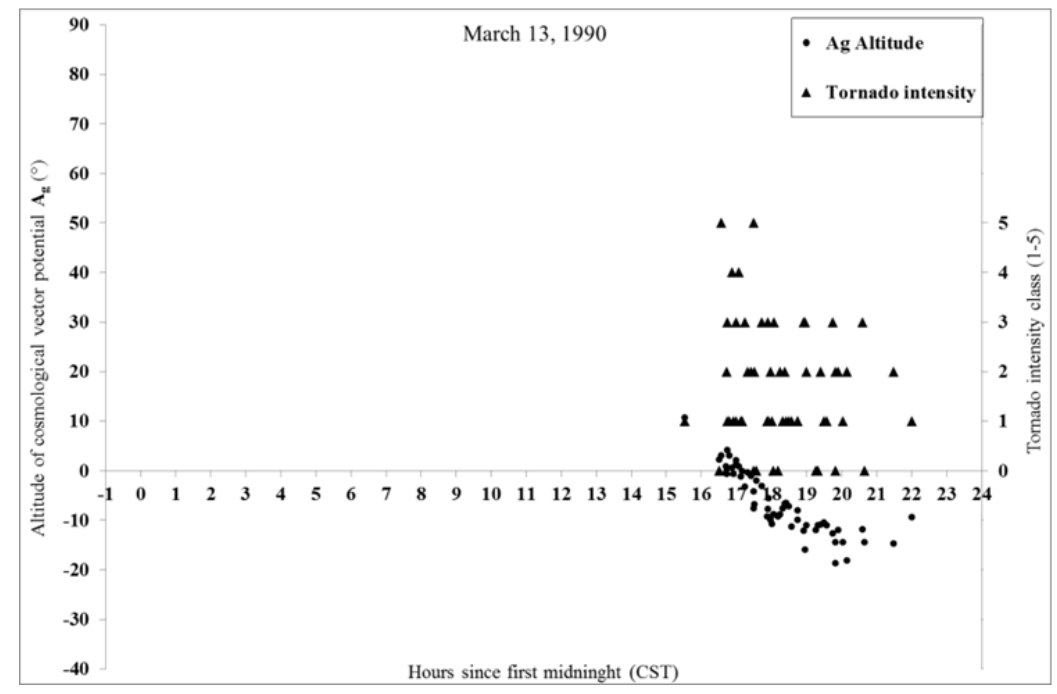

(a)

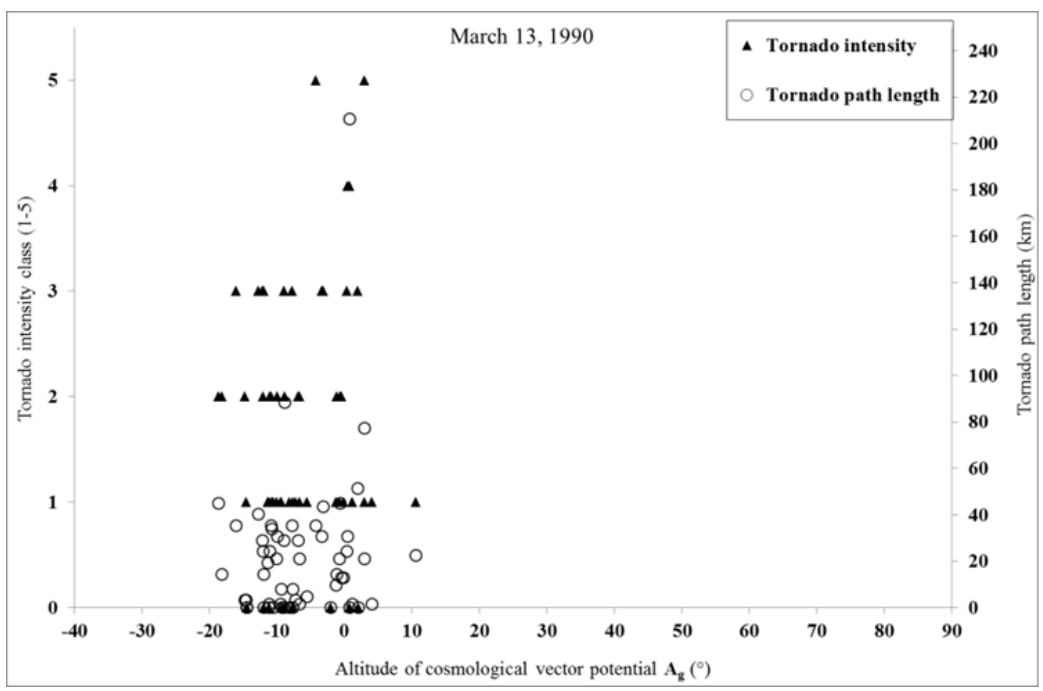

(b)

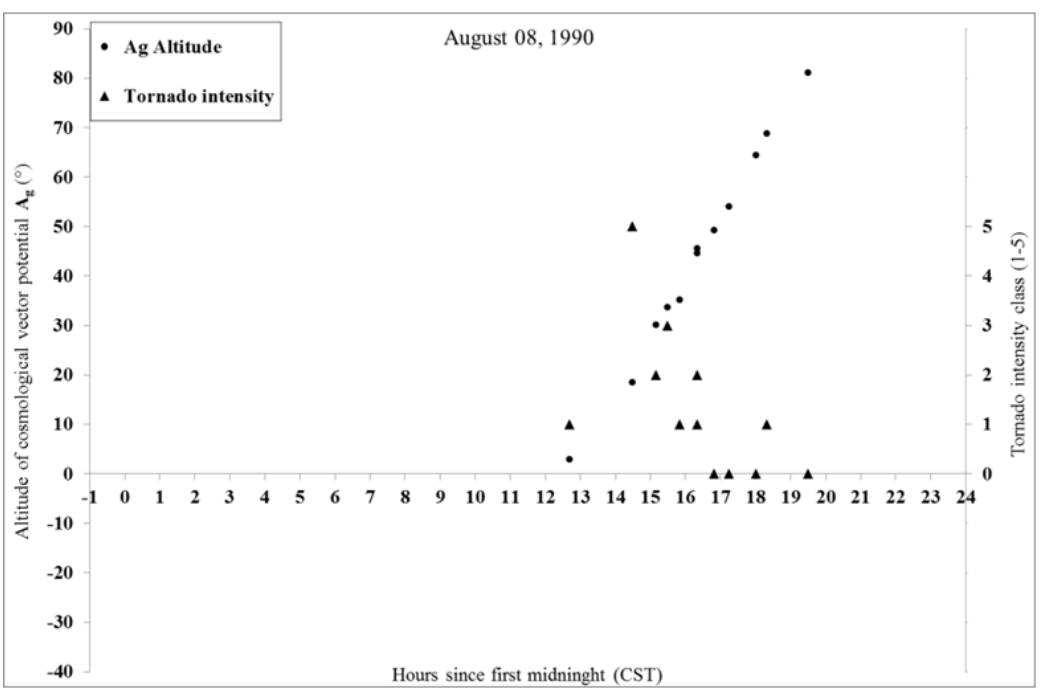

(c) 


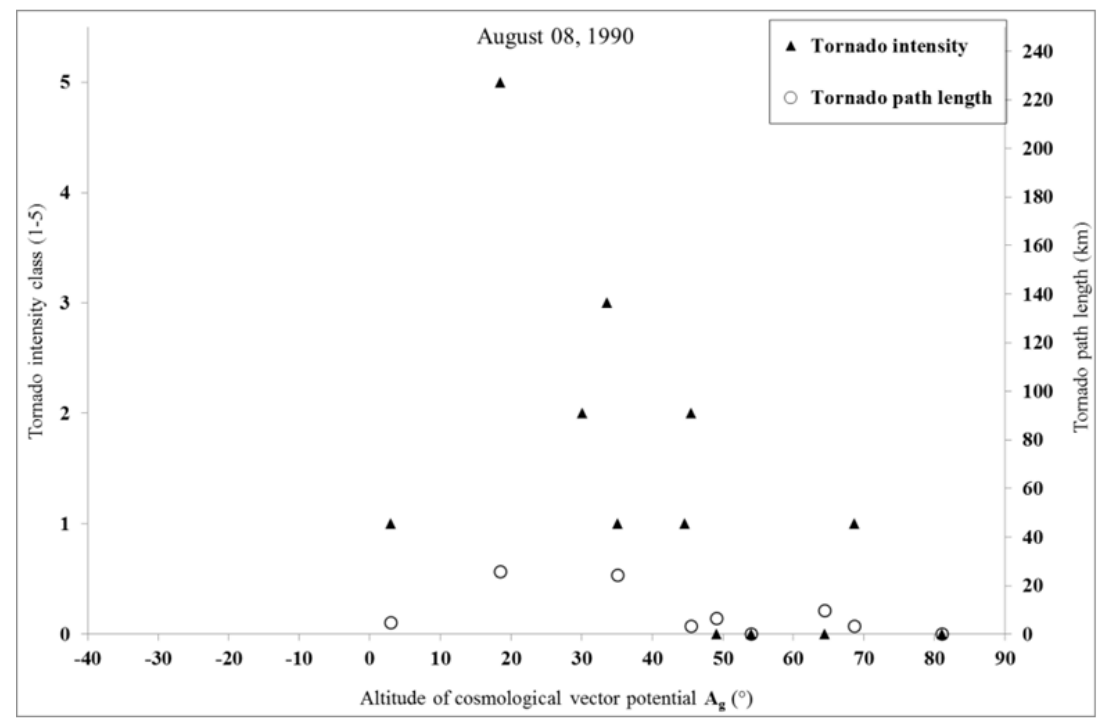

(d)

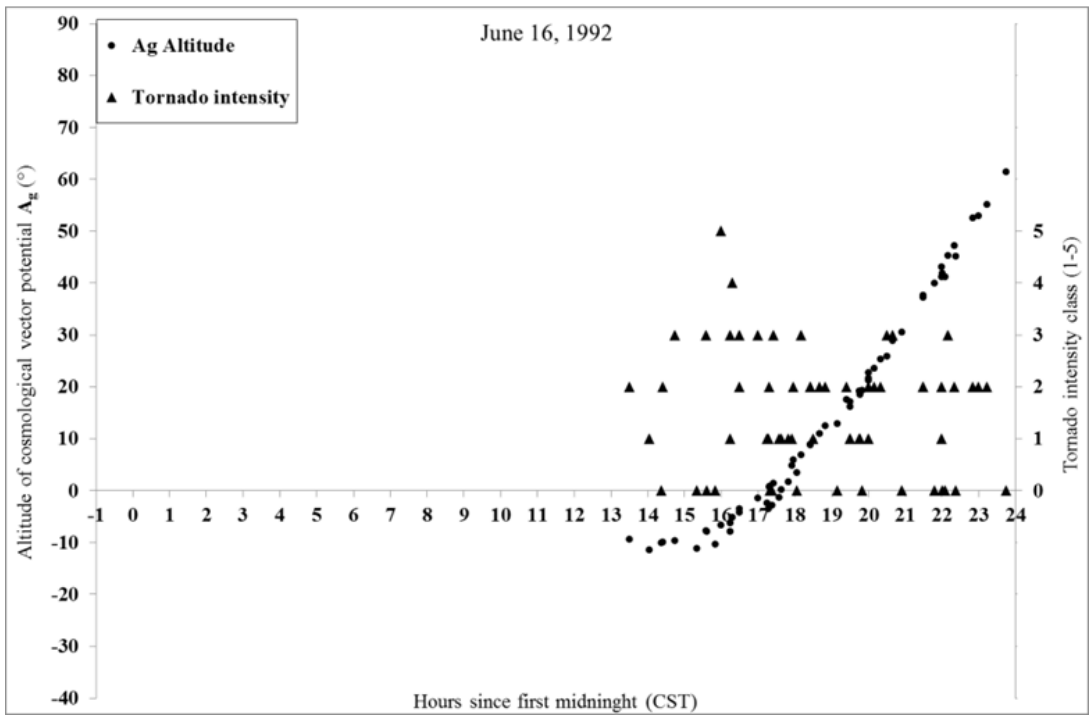

(e)

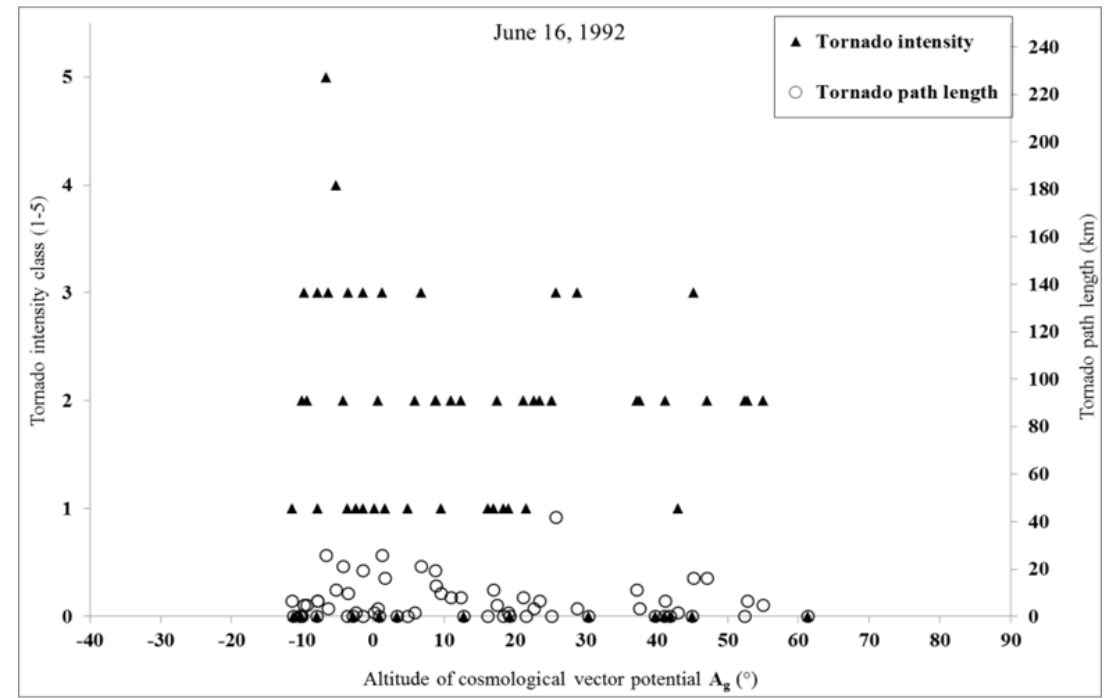

(f) 


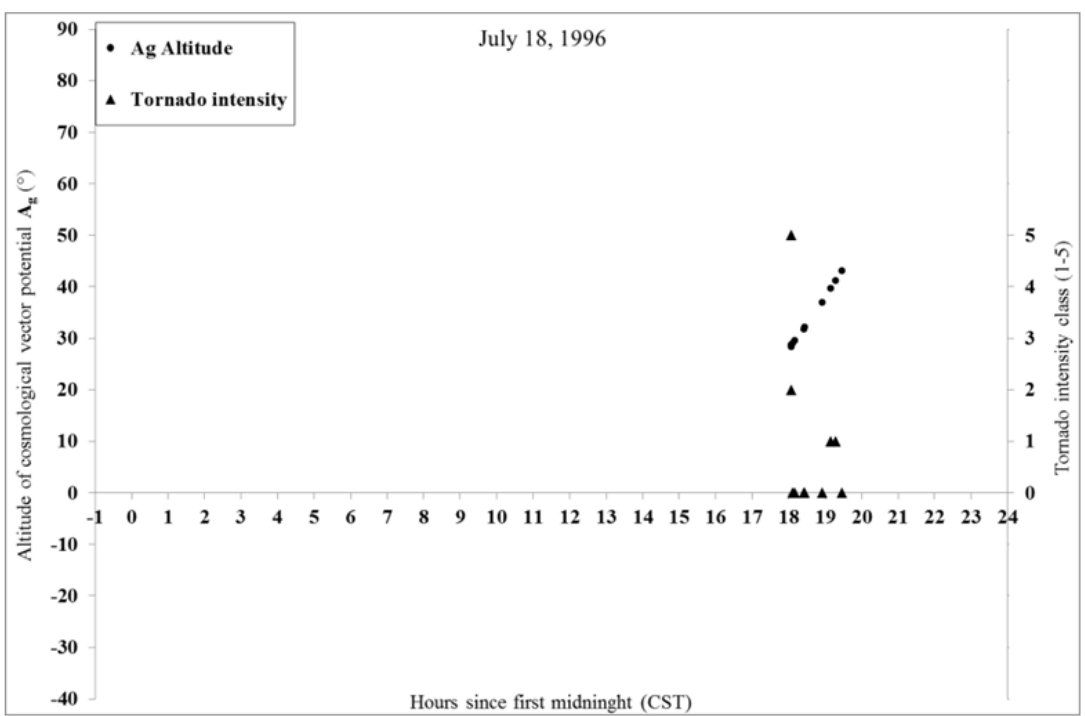

(g)

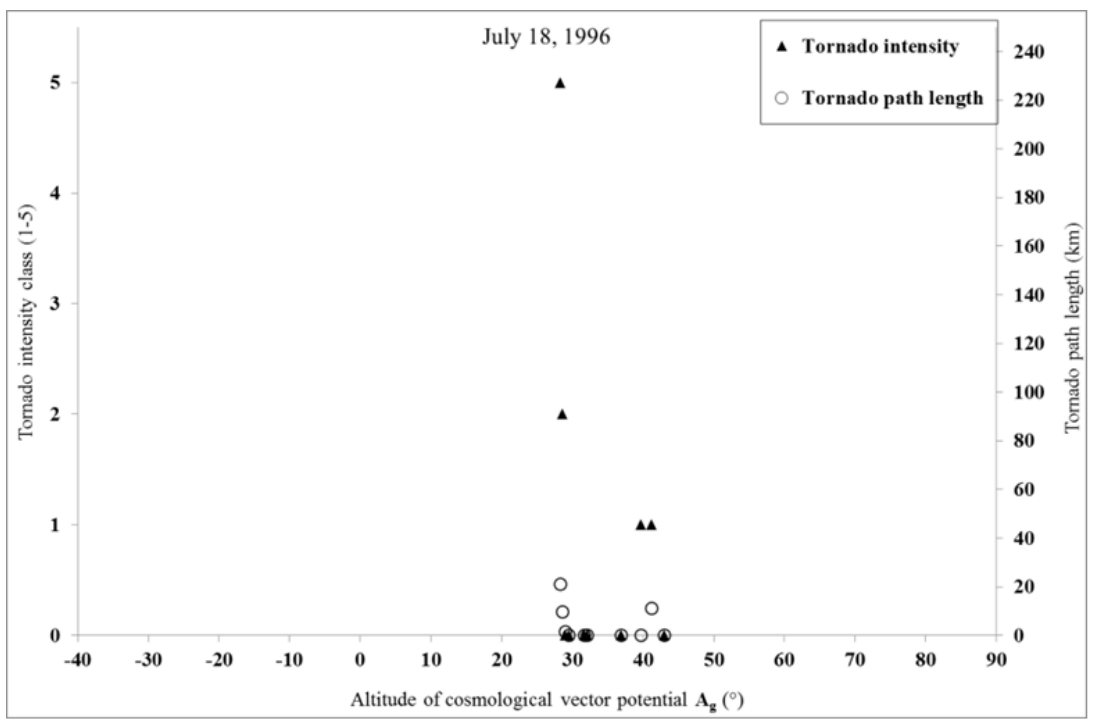

(h)

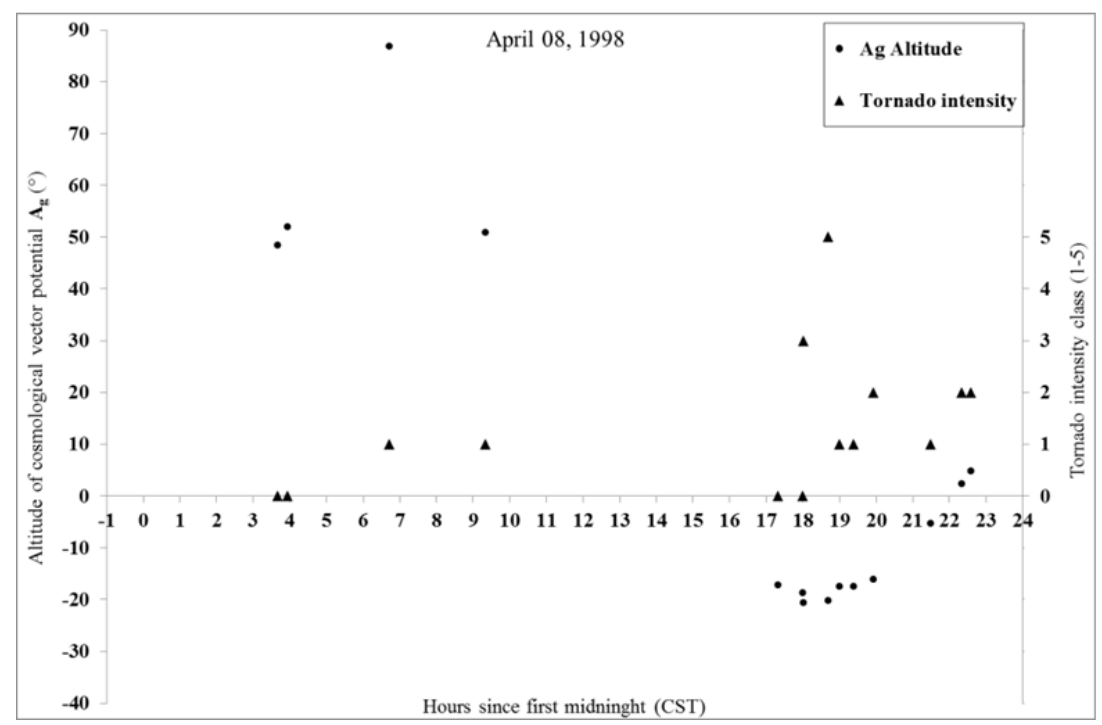

(i) 


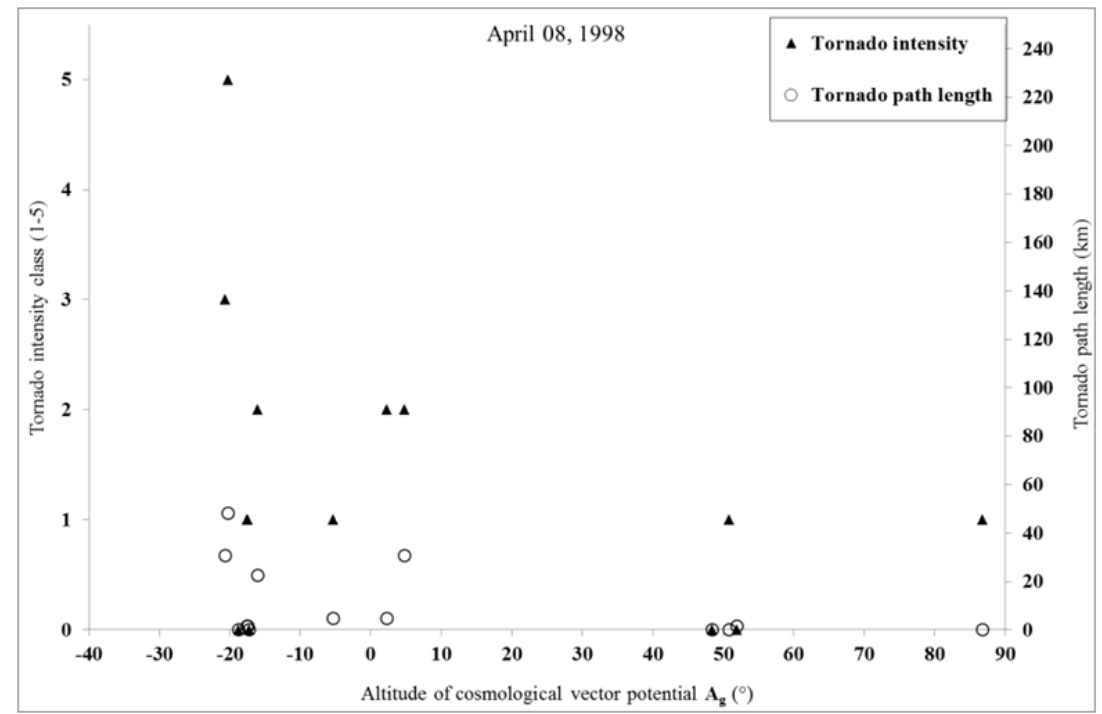

(j)

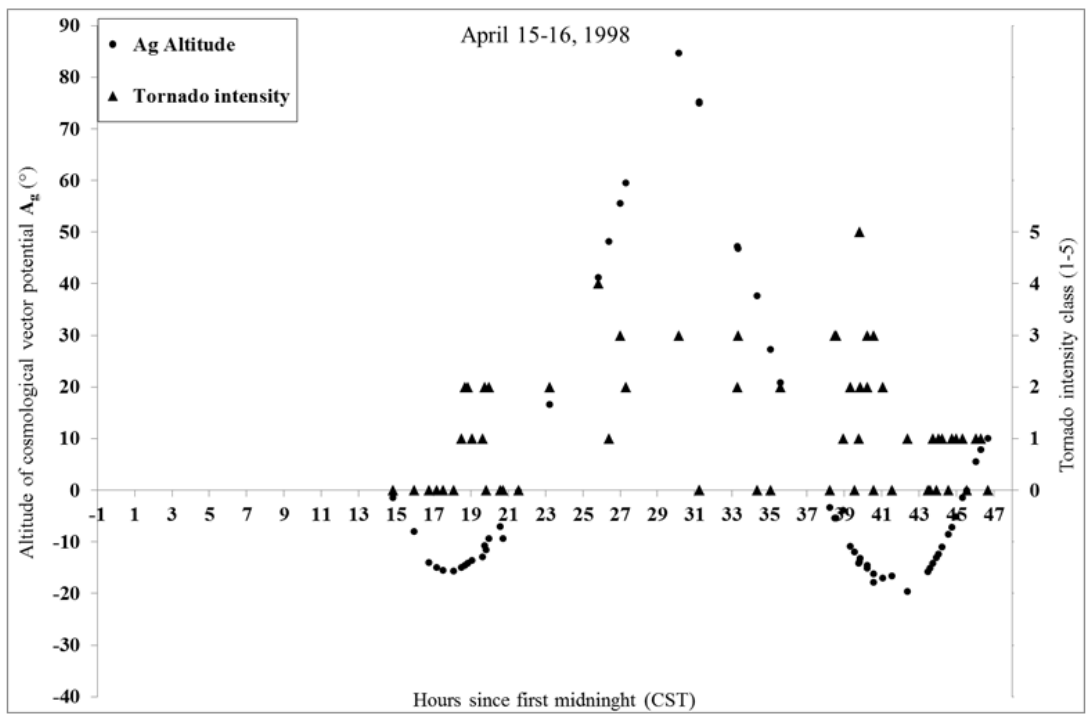

(k)

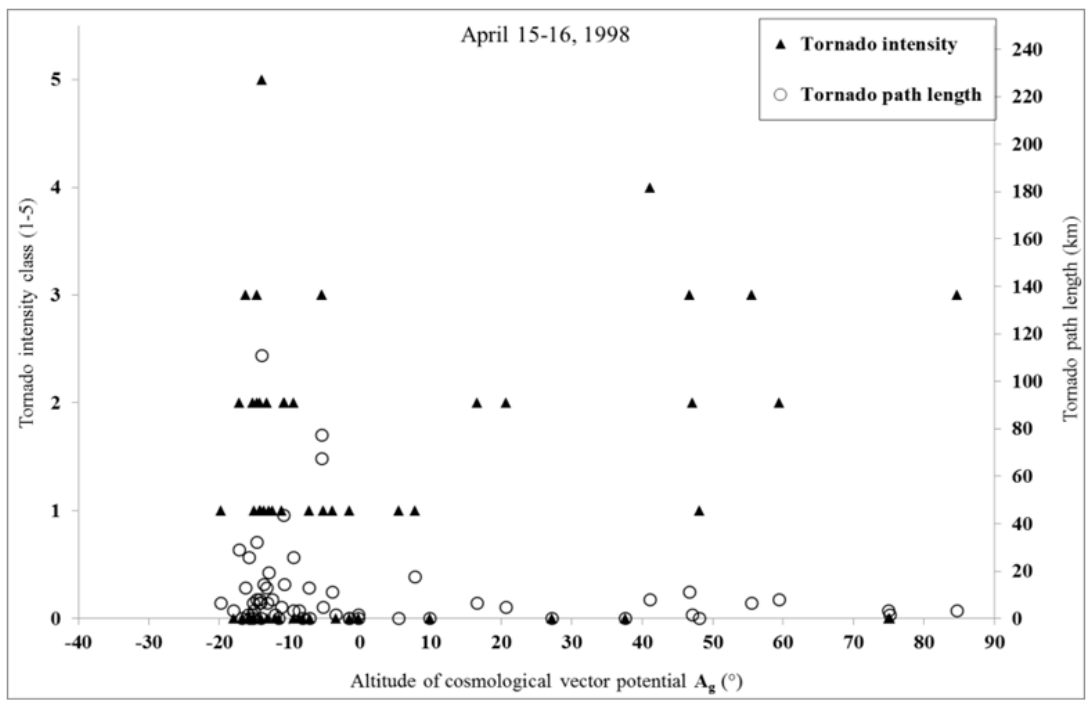

(1) 


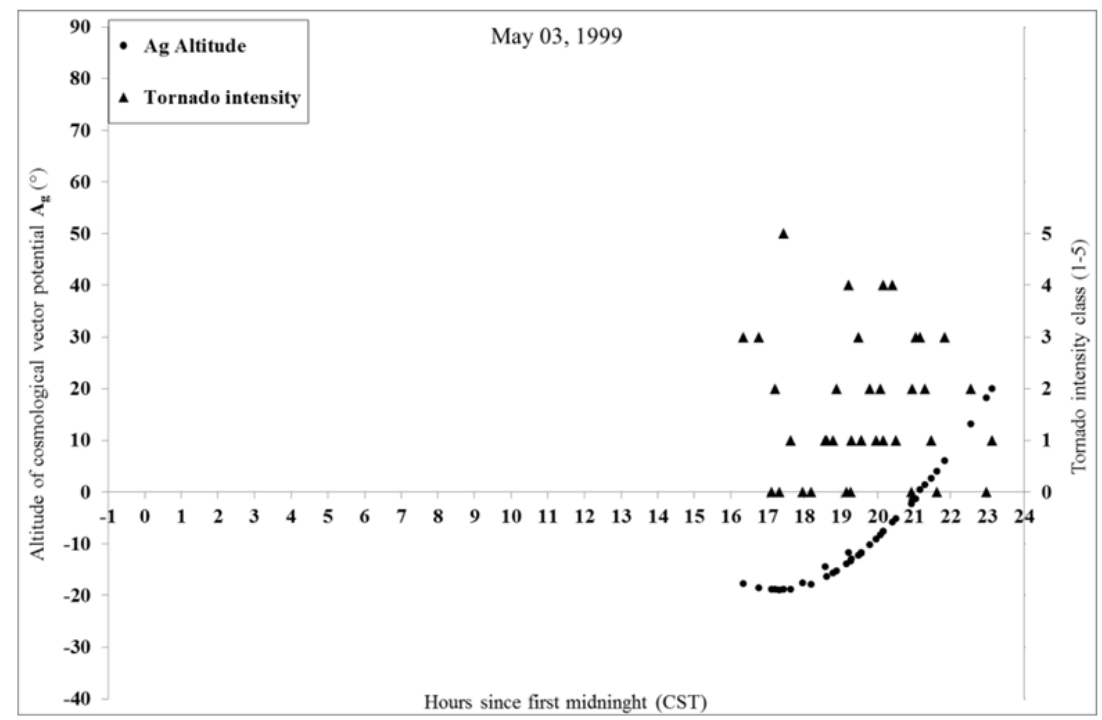

(m)

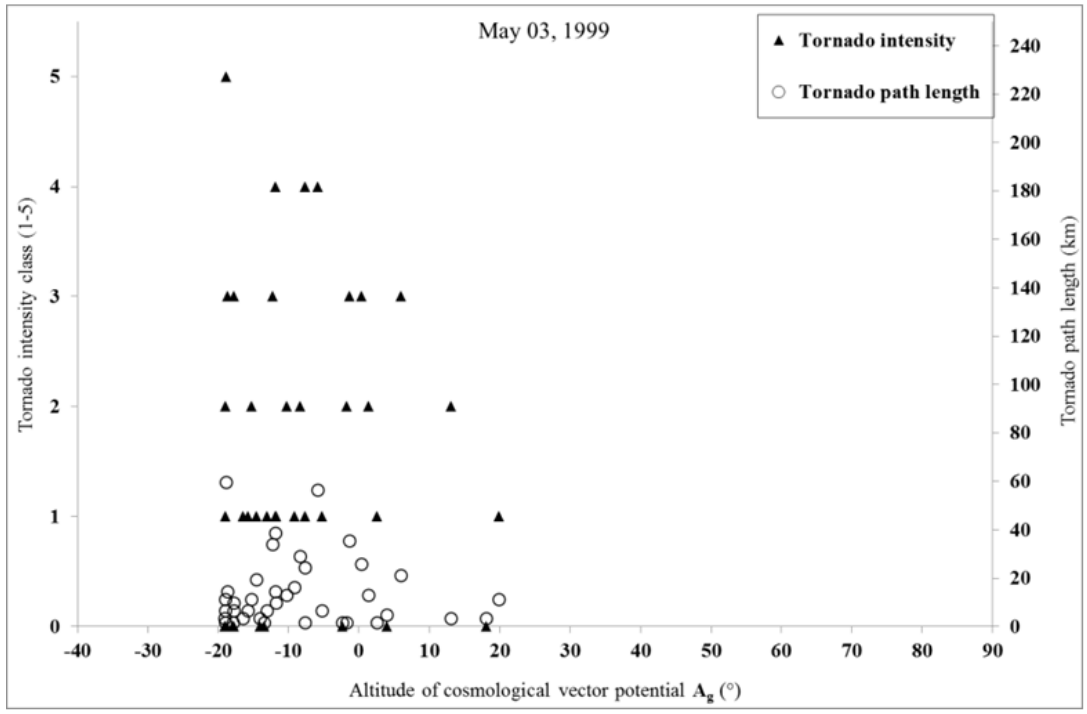

(n)

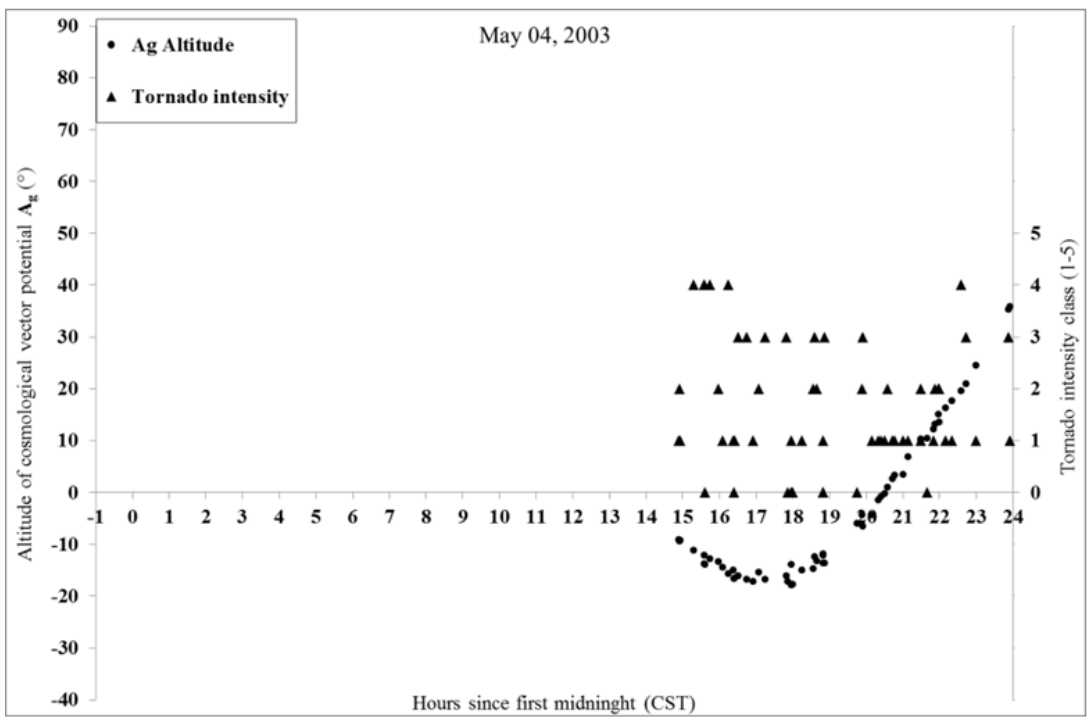

(o) 


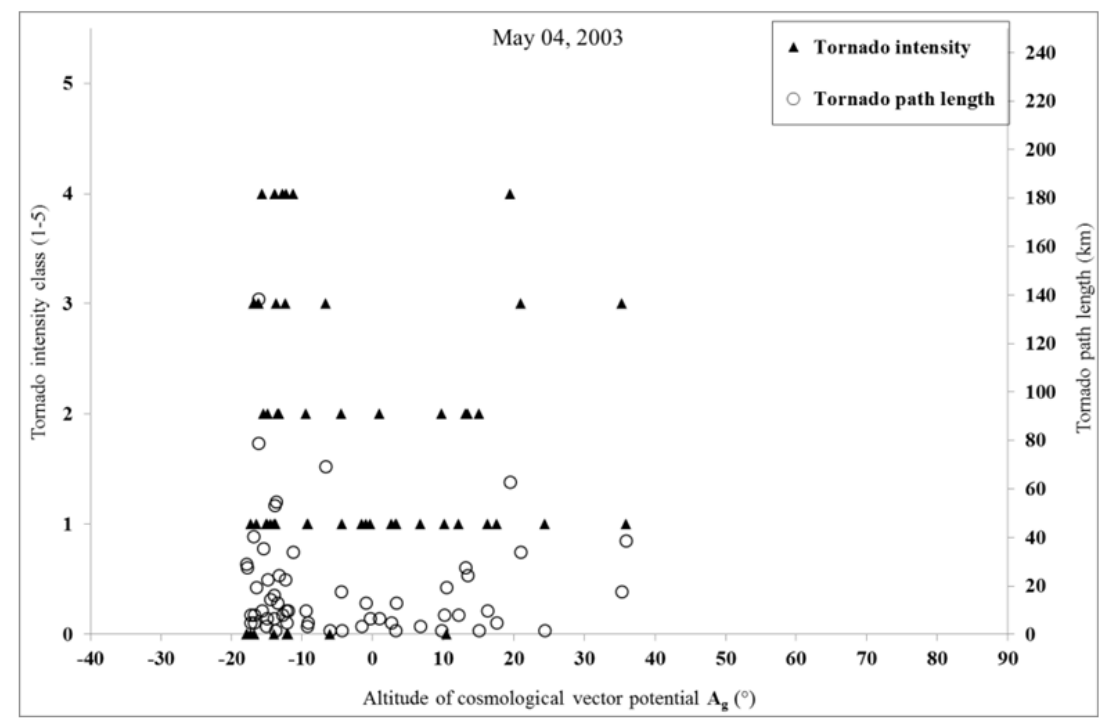

(p)

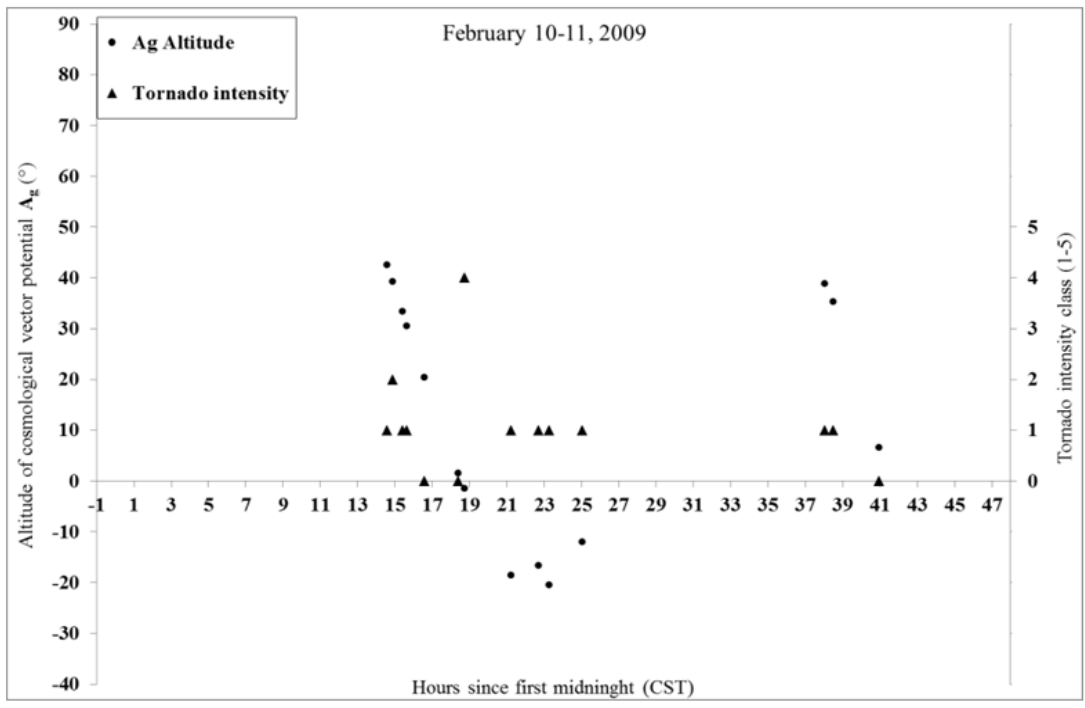

(q)

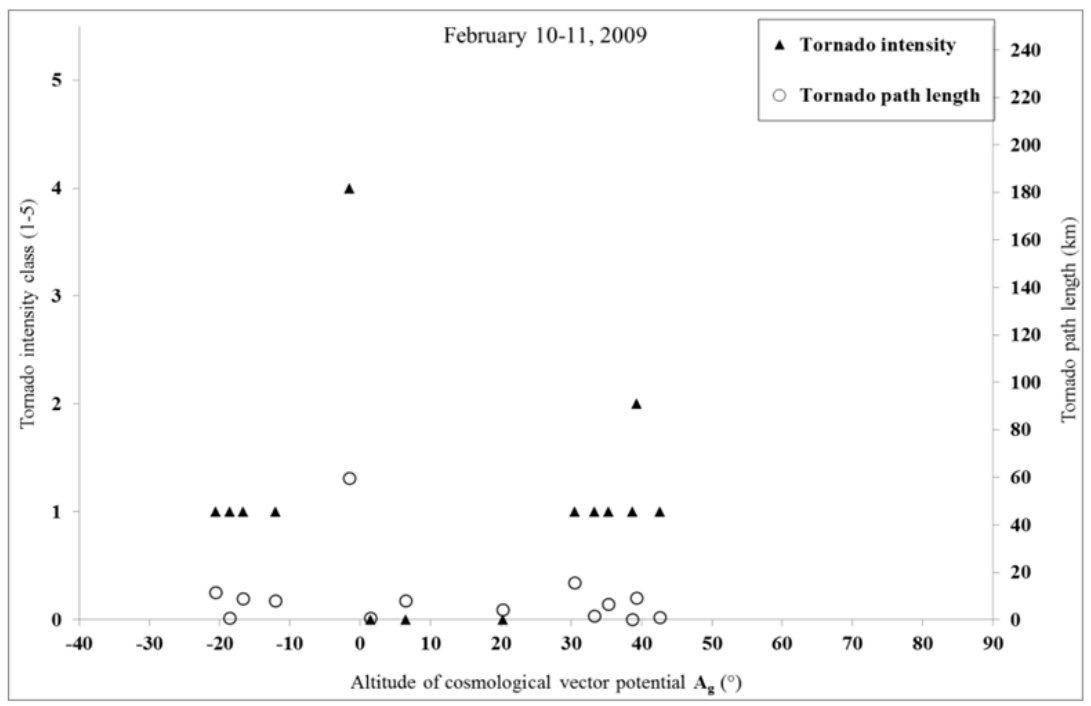

(r) 


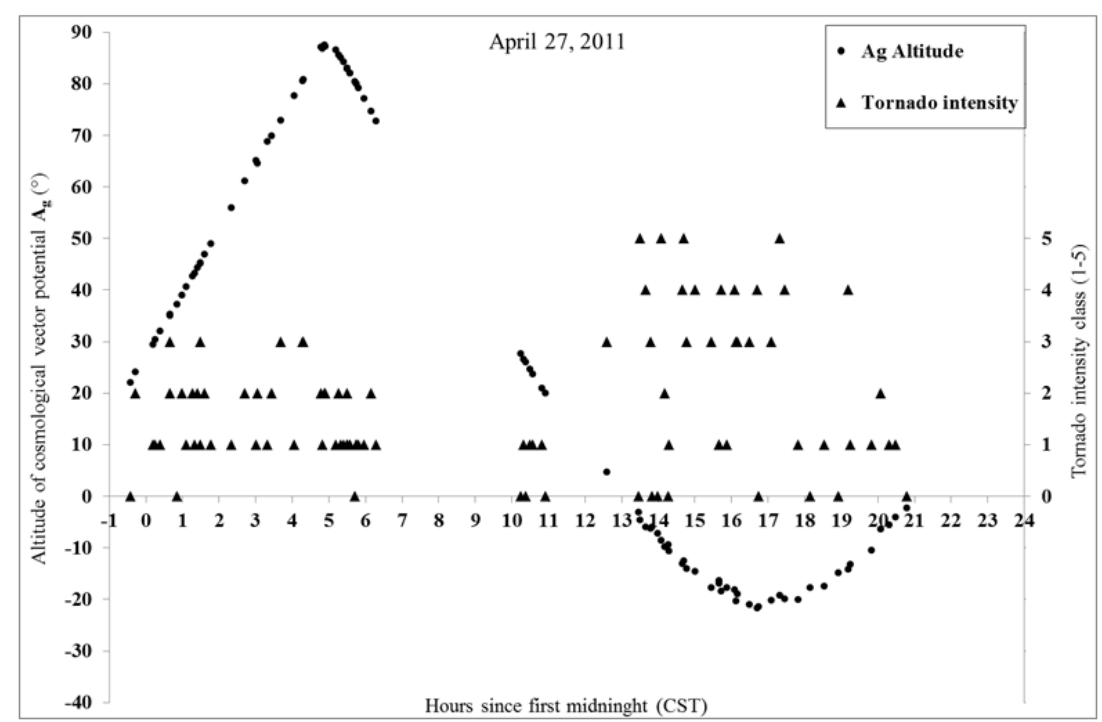

(s)

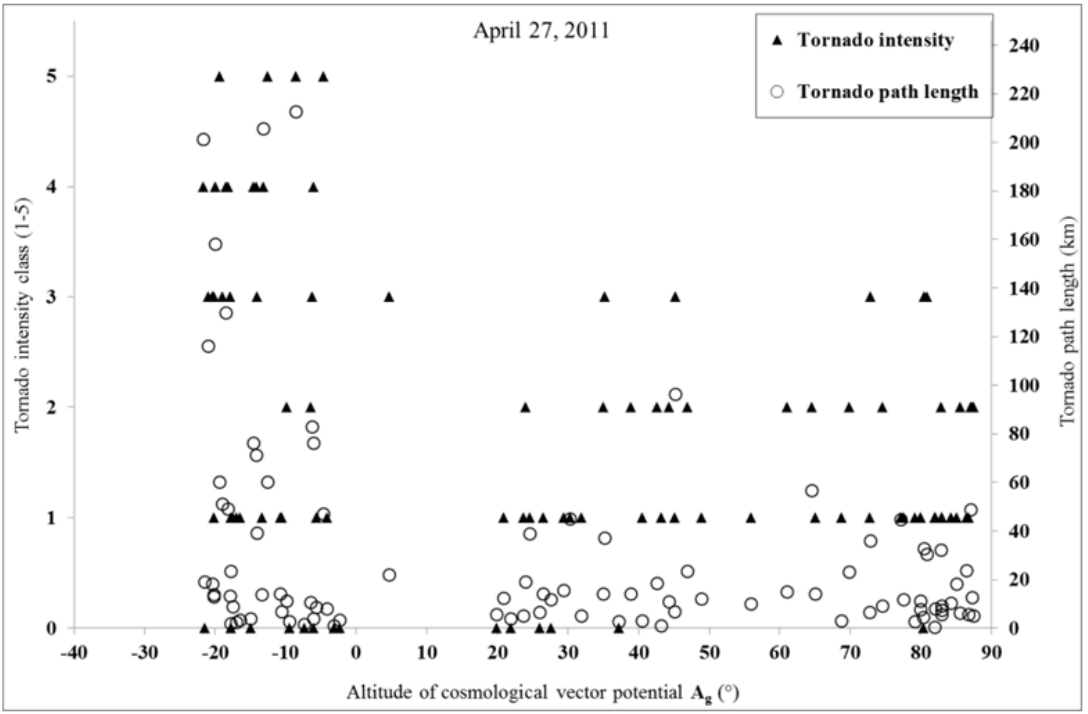

(t)

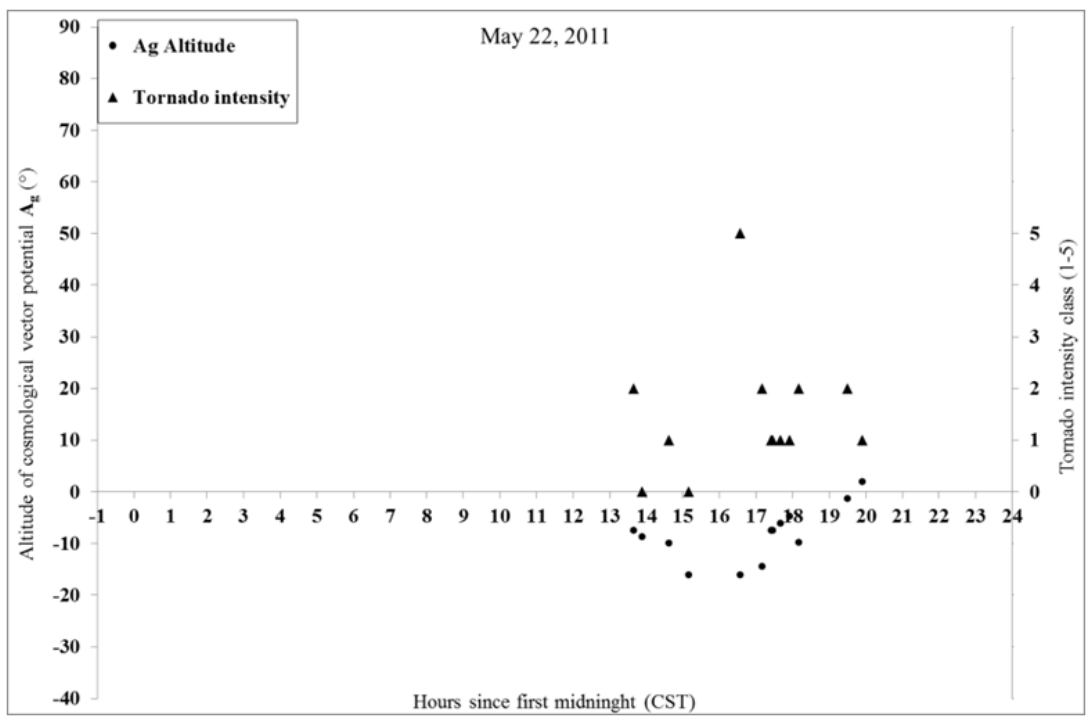

(u) 


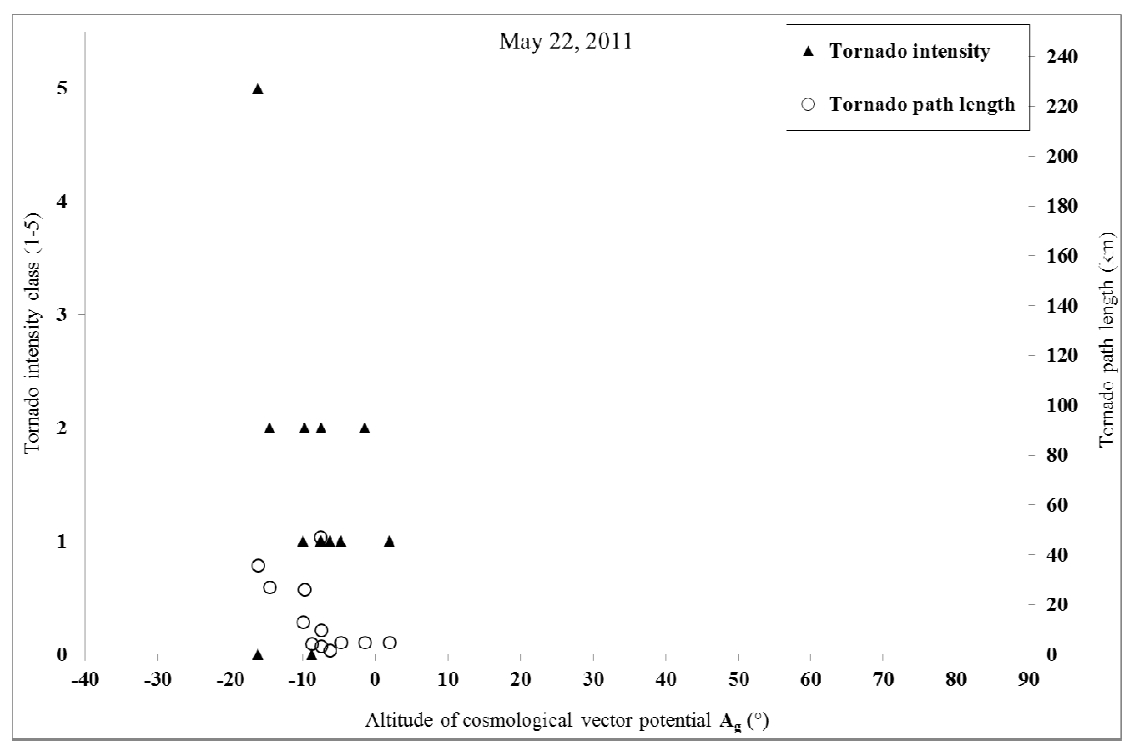

(v)

Fig. 6(a-v). Representation of the intensity class of each tornado in any outbreak along with the altitude of the cosmological vector potential $A_{g}$ at its touchdown at the respective local solar time (a,c,e,g,i,k,m,o,q,s) and of the tornado intensity class along with the respective path length against the altitude of $A_{g}(b, d, f, h, j, l, n, p, r, t)$.

A striking evidence arises from the tornado outbreaks represented in Fig. 6(a-v): despite the fact that the altitude of the cosmological vector potential $\mathrm{A}_{\mathrm{g}}$ performs a daily cycle, modulated by the different geographical coordinates of the single tornado events, covering practically any value in the range about $-30^{\circ}$ to $90^{\circ}$, all events with tornado intensity in the classes F4 and F5 with path length greater than $30 \mathrm{~km}$ occur when the altitude of $\mathrm{A}_{\mathrm{g}}$ is in the range $-20^{\circ}$ to $10^{\circ}$ with regards to the local horizontal plane, with the only exception of the outbreak hitting on May 4, 2003 (Fig. 6p) when an F4 tornado associated with a path length as long as $63 \mathrm{~km}$ occurred when the altitude of $\mathrm{A}_{\mathrm{g}}$ was anyway just less than $20^{\circ}$.

In the opinion of the authors, the combined evidences resulting from the analysis of Fig. 5(a), Fig. 5(b) and, likely more significant, Fig. 6(a-v), strongly support the hypothesized link between the occurrence of the most energetic tornadoes and the global anisotropy of the physical space, in turn adding confidence to the proposed model of intensification of this extremely powerful phenomenon of the Earth's atmosphere.

\section{Conclusions}

The main aim of this article was to investigate the possible relationship between the global anisotropy of the physical space and the occurrence of the most violent tornadoes.

The global anisotropy of the physical space was detected by means of a long series of experiments as well as observations of different natural systems at virtually any scale of the Universe, from the weak interaction to the metagalactic ones; on its basis the byuon theory (Section 3.1.) was built since the early 1990s'till a stage of development that allows to offer consistent explanations to a variety of physical phenomena covering the fields of nuclear physics, astrophysics, geophysics, as well as offers the chance to harness a new energy source[25,26,32].

So far, no weather phenomena were investigated on the basis of the byuon theory and this article aims to start covering the gap with the tornadoes which are likely the most powerful phenomena at scales from hundreds of meters to tenths of $\mathrm{km}$ in the Earth's atmosphere.

Although one can dispute the details of the proposed processes contributing to supply energy to developing tornadoes (Section 3.2.), the wide evidence provided in Section 4. for the link between the global anisotropy of the physical space and the occurrence of the most energetic tornadoes appears much more difficult to discard or to attribute to chance.

Despite the intrinsic huge complexity and chaotic nature of the atmosphere at any scale,on the basis of the analysis shown in this articleit is possible to statethat the most powerful tornadoes belonging to the F4 and F5 intensity classes as well as provided with path lengths greater than some thresholds specific to the intensity class occur only when the tangent to the local Earth's surface assumes sharply defined directionsin the Universe.

In other words, such tornadoes can occur only at specific times of the day which depend on latitude, longitude and day of the year as well as to the historical time, the latter affecting significantly only on the millennial scale.

All the above deriving from an universal physical constant, i.e. the cosmological vector potential $\mathrm{A}_{\mathrm{g}}$, similar conclusions are predicted to be valid even in extraterrestrial atmospheres, provided that the gravitational potential specific to any planet will represent another important variable in the picture.

Further verification can be performed increasing the database of tornadoes both in the herein considered U.S.A. territory and outside, e.g. in Europe, South America and other regions of the world. Moreover, as suggested 
inSchielicke and Névir[7], the tornado path width could be added to the relevant data to obtain a more accurate characterization of its overall energy and some summary energy index.

About the proposed processes allegedly contributing to the onset of tornadoes from very high peak current lightning discharges (Section 3.3.), the data presently available to the authors don't allow any useful verification; nevertheless, such processes are presented because they derive from the same fundamental physical theory which made possible the above discussed finding.On the other side, the need to verify this second class of processes can stimulate the optimization or the planning of both ground-based observation networks and dedicated satellite missions aimed at the detection and full characterization of the lightning dischargesin terms of nature $(+\mathrm{CG},-\mathrm{CG}, \mathrm{IC})$, location, peak current and detailed path.

Finally, if the processes contributing to the onset of tornadoes will be aswell verified, some inference could be drawn about the tornado hazard in the changing climate, in example in Mediterranean regions where $+\mathrm{CG}$ flashes were found to carry the largest peak currents in the winter months[12].

\section{Acknowledgments}

The authors gratefully acknowledge A. Crisci for valuable discussions at the early stage of their research,M. Pagliaro for the outstanding support and motivation by means of the SuNEC 2013 Conference, F. Zabini for assistance in the communication style of the manuscript.

\section{Appendix}

Abbreviations used in this article:

$\mathrm{A}_{\Sigma}=$ Summary vector potential $(\mathrm{T} \cdot \mathrm{m})$

$A_{g}=$ Cosmological vector potential $(\mathrm{T} \cdot \mathrm{m})$

$\mathrm{CDT}=$ Central Daylight Time

$\mathrm{CG}=$ Cloud-to-Ground lightning

$-\mathrm{CG}=$ Negative Cloud-to-Ground lightning

$+\mathrm{CG}=$ Positive Cloud-to-Ground lightning

$\mathrm{CST}=$ Central Standard Time

EST $=$ Eastern Standard Time

$\mathrm{IC}=$ Intra-Cloud lightning

$\mathrm{TD}=$ Touchdown

$\mathrm{TNT}=$ Trinitrotoluene

\section{References}

[1] S.A. Arsen'yev, "Mathematical modeling of tornadoes and squall storms", Geosci Front vol. 2, pp. 215-221, 2011.

[2] S.A. Arsen'yev, N.K. Shelkovnikov, "Electromagnetic fields in tornados and spouts" Moscow Univ Phys Bull, vol. 67:pp. 290-295, 2012.

[3] A.Y. Gubar, A.I. Avetisyan, V.V. Babkova, "Tornado rise: 3D numerical model in the mesoscale turbulence theory of Nikolaevskiy", Dokl Earth Sci, vol. 419, pp. 467-472, 2008
[4] N. Kufa, R. Snow, "Lightning: meteorology's new tool. 86th AMS Annu. Meet. (Atlanta, GA)". Second Conf. Meteorol. Appl. Light. Data, American Meteorological Society; 2006.

[5] A.J. Litta, U.C. Mohanty, S. Kiran Prasad, M. Mohapatra, A. Tyagi, S.C. Sahu, "Simulation of tornado over Orissa (India) on March 31, 2009, using WRF-NMM model. Nat Hazards", vol. 61 , pp. 1219-1242, 2011

[6] A.E. Mercer, C.M. Shafer, C.A. Doswell, L.M. Leslie, M.B. Richman, "Objective Classification of Tornadic and Nontornadic Severe Weather Outbreaks". Mon Weather Rev, vol. 137, pp. 4355-4368, 2009

[7] L. Schielicke, P. Névir, "Comprehensive analysis of tornado statistics in comparison to earthquakes: intensity and temporal behaviour", Nonlinear Process Geophys, vol. 20, pp. $47-57,2013$

[8] V.I. Ermakov, Y.I. Stozhkov, "Thunderstorm Cloud Physics". Moscow (in Russian). Available at: Http://ellphi.lebedev.ru/wpcontent/uploads/2011/12/2004_2.pdf: 2004.

[9] A. Nag, V.A. Rakov, "Positive lightning: An overview, new observations, and inferences", J Geophys Res, 117:D08109, 2012.

[10] C.G. Price, "Lightning Applications in Weather and Climate Research". Surv Geophys, vol. 34, pp. 755-767, 2013.

[11] W. Lyons, T. Nelson, E. Williams, J. Cramer, T. Turner, "Enhanced positive cloud-to-ground lightning in thunderstorms ingesting smoke from fires". Science, vol. 282, pp. 77-80, 1998.

[12] T.G. Chronis, "Preliminary lightning observations over Greece", J Geophys Res 117:D03113, 2012.

[13] T.C. Marshall, M. Stolzenburg, "Voltages inside and just above thunderstorms", J Geophys Res, vol. 106, pp. 47574768, 2001.

[14] C. R. Maggio, T.C. Marshall, M. Stolzenburg, "Estimations of charge transferred and energy released by lightning flashes", J Geophys Res, 114:D14203, 2009.

[15] A.H. Perez, L.J. Wicker, R.E. Orville, "Characteristics of Cloud-to-Ground Lightning Associated with Violent Tornadoes". Weather Forecast, vol. 12, pp. 428-437, 1997.

[16] A. Seimon, "Anomalous Cloud-to-Ground Lightning in an F5-Tornado-Producing Supercell Thunderstorm on 28 August 1990", Bull Am Meteorol Soc, vol. 74, pp. 189-203, 1993.

[17] L.D. Carey, W.A. Petersen, S.A. Rutledge, "Evolution of Cloud-to-Ground Lightning and Storm Structure in the Spencer, South Dakota, Tornadic Supercell of 30 May 1998", Mon Weather Rev, vol. 131, pp. 1811-1831, 2003.

[18] Storm Prediction Center WCM Page, http://www.spc.noaa.gov/wcm/\#data(last accessed: November 16, 2013.

[19] Tornado history project, http://www.tornadohistoryproject.com/(last accessed: November16, 2013).

[20] Yu. A. Baurov, E.Yu. Klimenko, S.I. Novikov, "Experimental observation of space magnetic anisotropy", Phys Lett A, vol. 162, pp. 32-34, 1992. 
[21] Yu.A. Baurov, "Space magnetic anisotropy and a new interaction in nature", Phys Lett A, vol. 181, pp. 283-288, 1993

[22] Yu. A. Baurov, A.A. Konradov, V.F. Kushniruk, E.A. Kuznetsov, Yu.G. Sobolev, Yu. V. Ryabov, et al. "Experimental investigations of changes in beta-decay rate of 60Co and 137Cs", Mod. Phys. Lett. A, vol. 16, pp. 20892101,2001

[23] I.F. Malov, Yu.A. Baurov, "The distribution of space velocities of radio pulsars", Astron Reports, vol. 51, pp. 830-835, 2007.

[24] Yu.A. Baurov, "The Anisotropy of Cosmic Rays and the Global Anisotropy of Physical Space", J. Mod. Phys., vol. 3, pp. 1744-1748, 2012.

[25] Yu.A. Baurov, On the structure of physical vacuum and a new interaction in Nature (Theory, Experiment and Applications). NY: Nova Science; 2000.

[26] Yu.A. Baurov, Global Anisotropy of Physical Space, Experimental and Theoretical Basis. NY: Nova Science; 2004.

[27] Yu.A. Baurov, I.F. Malov, "On the Nature of Dark Matter and Dark Energy", J. Mod. Phys., vol. 1, pp. 17-32, 2010.

[28] Yu.A. Baurov, I.F. Malov, "Variations of Decay Rates of Radio-active Elements and their Connections with Global Anisotropy of Physical Space", Int. J. Pure Appl. Phys., vol. 6,pp. 469-482, 2010; Also at: http://arxiv.org/abs/1001.5383.

[29] Yu.A. Baurov, I.B. Timofeev, V.A. Chernikov, S.F. Chalkin, A.A. Konradov, "Experimental investigations of the distribution of pulsed-plasma-generator radiation at its various spatial orientation and global anisotropy of space", Phys. Lett. A, vol. 311,pp. 512-523, 2003.

[30] Yu.A. Baurov, Yu.G. Sobolev, Yu.V. Ryabov, V.F. Kushniruk, "Experimental investigations of changes in the rate of beta decay of radioactive elements", Phys. At Nucl., vol. 70, pp. 1825-1835, 2007.
[31] P.A. Sturrock, J.B. Buncher, E. Fischbach, II. D. Javorsek, J.H. Jenkins, J.J. Mattes, "Concerning the Phases of the Annual Variations of Nuclear Decay Rates", Astrophys J., vol. 737 , p. $65,2011$.

[32] Yu.A. Baurov, "Research of global anisotropy of physical space based on investigation of changes in $\beta$ and $\alpha$-decay rate of radioactive elements, motion of pulsars and anisotropy of cosmic rays", Am. J. Mod. Phys., vol. 2, pp. 177-184, 2013

[33] Yu.A. Baurov, A.A. Spitalnaya, A.A. Abramayan, V.A. Solodovnikov, "Seismic activity of the earth, the cosmological vectorial potential and method of a short-term earthquakes forecasting", Nat. Sci., vol. 3,pp. 109-119, 2011.

[34] Yu.A. Baurov, F. Meneguzzo, A.Yu. Baurov, A.Yu. Baurov(j), "Plasma Vacuum Bubbles and a New Force of Nature, The Experiments", Int. J. Pure Appl. Sci. Technol., vol. 11,pp. 34-44, 2012.

[35] Yu. A. Baurov, A.G. Znak, V.G. Farafonov, "Experimental Investigation of Heat Content in the Jet of Magnetoplasmadynamic Accelerator in Accordance with its Spatial Orientation", Adv. Plasma Phys. Res., New York: Nova Science Publishers Inc; pp. vol. 5, pp. 179-96, 2007.

[36] T.A. Deecke, J.V. Hyde, J.M. Hylko, "Packaging waste and hitting home runs: how education and lightning strike detection technology supports company and community activities", WM'06 Conf. Febr. 26-March 2, 2006, Tucson, AZ. Available http//www.wmsym.org/archives/2006/pdfs/6070.pdf, Tucson, AZ: 2006, p. 23.

[37] L.D. Carey, "Lightning location relative to storm structure in a leading-line, trailing-stratiform mesoscale convective system", J. Geophys Res.,110:D03105.,2005.

[38] S.J. Goodman, R.J. Blakeslee, W.J. Koshak, D. Mach, J. Bailey, D. Buechler, et al. "The GOES-R Geostationary Lightning Mapper (GLM)", Atmos. Res., pp. 125-126; pp. $34-49,2013$. 